\title{
Comportamento informacional em teses e dissertações na ciência da informação no Brasil entre 2007-2012: Revisão de literatura
}

\author{
Vitor Taga \\ Ursula Blattmann \\ Universidade Federal de Santa Catarina - UFSC. Brasil
}

ARTIGO / ARTICLE

\begin{abstract}
Resumo
Estudos sobre comportamento informacional têm atraído o interesse de diversas áreas do conhecimento, entre elas a Ciência da Informação. Realizou-se uma pesquisa documental exaustiva em âmbito brasileiro, das teses e dissertações apresentadas nos onze Programas de Pós-Graduação de Ciência da Informação, defendidas no período de 2007 a abril de 2012. Foi identificado um total de 465 dissertações e 157 teses publicadas no respectivo período. Ao aplicar a escolha dos seguintes termos no título e palavras-chave: Comportamento Informacional; Comportamento de Busca da Informação; Necessidade de Informação; Estudo de Usuários; Busca da Informação; Acesso à informação; Uso da Informação; Necessidade, Busca, Acesso e Uso da Informação; Sense-Making; Tomada de decisão; e, Recuperação da Informação obteve-se para a análise 88 dissertações e 17 teses. Os termos com maior ocorrência no título foram: Tomada de Decisão (11), Comportamento Informacional (10) e Recuperação da Informação (10). Cabe salientar que, nas palavras-chave a Recuperação da Informação (49) teve a maior ocorrência entre os termos, seguida de Estudo de Usuários (19), Comportamento informacional (15), Necessidade de Informação (12), e Tomada de Decisão (10). A média de 19 documentos publicados por ano entre 2007 e 2010 . O estudo identificou os autores, os orientadores e gerou um grafo no qual se percebe o posicionamento central de seis orientadores: Ricardo Barbosa (UFMG), Mônica Erichsen Nassif Borges (UFMG), Murilo Bastos da Cunha (UNB), Emir José Suaiden (UNB), Helen de Castro Silva Casarin (UNESP), Isa Maria Freire (UFF / UFPB). A temática comportamento informacional aparece com maior ocorrência nas instituições: UFMG, UNB, UNESP e UFPB. A pesquisa demonstrou a continuidade de estudos na área e apontaram que aproximadamente $1 / 5$ das dissertações e $1 / 10$ das teses brasileiras abrangem.
\end{abstract}

Palavras-chave

Comportamento informacional ; Comportamento de busca de informação ; Busca da informação ; Uso da informação ; Necessidade de informação ; Estudo de usuários

\section{Information behavior inside brazilian's information science dissertations and thesis from 2007-2012: Literature review}

\footnotetext{
Abstract

Studies of information behavior have attracted interest from several areas of knowledge, including information science. We conducted an exhaustive documentary research into dissertations and thesis published in eleven brazilian Post-Graduate Programs in Information Science, from 2007 to april 2012. Were identified a total of 465 thesis and 157 thesis published in the respective period. By applying the choice of the following terms in the title and keywords: Informational Behavior; Information Seeking-Behavior; Information Needs; User Studies; Information Seeking; Information Access; Use of Information; Needs, Seeking, Access and Use of Information; Sense-Making; Decision Making; and Information Retrieval was obtained 88 thesis and 17 dissertations for analysis. The most occurred terms in the title were: Decision Making (11), Information Behavior (10) and Information Retrieval (10). It should be noted that in the keywords Information Retrieval (49) had the highest frequency of occurrence between terms, followed by User Studies (19), Information Behavior (15), Information Needs (12), Decision Making (10). The average between 2007 and 2010 was 19 published papers per year. The study identified the published work advisors
} 
and generate a graph which shows the central position of six advisors: Ricardo Barbosa (UFMG), Monica Nassif Erichsen Borges (UFMG), Murilo Bastos da Cunha (UNB), Emir Jose Suaiden ( UNB), Helen de Castro Silva Casarin (UNESP), Isa Maria Freire (UFF / UFPB). The information behavior theme appears with more frequently in the follow institutions: UFMG, UNB, UNESP and UFPB. The survey showed the continuity studies in this area and pointed out that approximately one fifth of thesis and $1 / 10$ of dissertations studies cover this area in Brazil.

\section{Keywords}

Information behavior ; Information seeking-behavior ; Information seeking ; Use of information ; Information needs ; User studies

\section{Introdução}

As primeiras pesquisas sistemáticas em comportamento informacional remontam aproximadamente um século, originam-se no contexto das bibliotecas, mídias de massa e estudos sobre leitores, oriundos de trabalhos voltados para o uso de fontes de informação, como livros e revistas (CASE, 2002; BATES, 2010). Em geral, estes estudos estavam mais preocupados com problemas referentes à classe social dos usuários e menos preocupados com as necessidades que levavam as pessoas a utilizarem a biblioteca, por exemplo, como fonte de informação (WILSON, 1999).

Pettigrew, Fidel e Bruce (2001 apud FIDEL et al., 2004) observam que os estudos de comportamento informacional e de usuários têm expandido, especialmente, nas últimas décadas contribuindo, inclusive, para a consolidação e desenvolvimento de teorias e conceitos.

O estudo de comportamento informacional tornou-se uma área de pesquisa bem definida dentro da Ciência da Informação. Outras disciplinas também têm interesse em usuário e o uso da informação, segundo Wilson (2000).

A fim de compreender os diversos aspectos envolvidos no comportamento informacional, ao longo de anos, vários modelos foram propostos como tentativas de esclarecer, caracterizar e predizer o comportamento informacional, em maior ou menor grau, as fontes e/ou canais de informação que as pessoas utilizam e têm êxito no acesso à informação, a interação entre as pessoas e sistemas de informação, e conseqüentemente, com a própria informação, explorando questões e áreas previamente não tão bem entendidas.

Temos por referência clássica a abordagem de Níveis de Necessidades Informacionais de Robert Taylor (1967), a Hipótese de Estado Anômalo de Conhecimento (ASK) de Nicholas Belkin (1980), Abordagem SenseMaking de Brenda Dervin (1983, 1992), Processo de Busca da Informação (ISP) de Carol Kuhlthau (1991), os modelos de Tom D. Wilson de Comportamento de Busca da Informação (1981) e o Modelo Geral de Comportamento Informacional (1997), e modelo de Resolução de Problema (1999), e a Análise Cognitiva do Trabalho (CWA) introduzida por Fidel e Pjetersen (2004).

Uma das razões da dimensão adquirida por esses modelos encontra-se na viabilidade de aplicação desses modelos em situações e contextos gerais de busca da informação (XIE, 2008). Wilson (1999) e Xie (2008) consideram estas abordagens como complementares e/ou inter-relacionadas.

Segundo Xie (2008) estas abordagens influenciaram e tornaram-se bases teóricas para abordagens recentes e no desenvolvimento de modelos macro e micro de recuperação interativa da informação, além de estarem continuamente sendo validadas e reforçadas, seja pelos seus criadores como por outros pesquisadores em diversos estudos, ao considerá-las abordagens que podem ser aplicadas para situações gerais de busca/recuperação da informação embora possam ser originalmente derivadas de um grupo específico de usuários.

Xie (2008) justifica-se por meio dos dados oferecidos pela Social Science Citation, que apresentam a amplitude das citações que estas abordagens têm tido nas pesquisas, seja como frameworks teóricos, como para orientação prática. 
Neste contexto, o presente estudo propôs identificar pela pesquisa documental as teses e dissertações publicadas nos Programas de Pós-Graduação em Ciência da Informação no Brasil, no período de 2007 a abril de 2012 contextualizando os termos nos títulos e nas palavras-chaves, os autores, os orientadores e as instituições de ensino e pesquisa com o foco em Comportamento Informacional.

\section{Comportamento informacional}

O marco inicial dos estudos voltados para o comportamento informacional remete ao ano de 1948, ano que foi realizada a Conferência da Royal Society Information. As experiências associadas à criação da "Grande Ciência" (tradução de Big Science) durante a Segundo Guerra Mundial mobilizaram líderes de governo a enxergarem as vantagens em melhorar a distribuição e a transferência da informação entre novas descobertas de cientistas e engenheiros (WILSON, 1999; CRESPO; CAREGNATO, 2006; HERNÁNDEZ SALAZAR et al., 2007; BATES, 2010).

Conforme Araújo (2008), no período pós-guerra, que inicia a Guerra Fria, o contexto sócio-político delineava e influenciava as pesquisas em diversas áreas do conhecimento, que refletiu também nas questões de estudos de usuários.

Segundo Case (2002, p. 6), somente na década de 1970 as investigações começam a ramificar para além do foco em canais formais e "necessidades orientadas a tarefas" (tradução de task-oriented needs). A ênfase desloca-se dos sistemas de informação estruturados para as pessoas como inventores, criadores, e usuários de informação. Mesmo os estudos de sistemas formais de informação começam a considerar uma ampla gama de pessoas, problemas e necessidades mais gerais, e as formas que cada um desses sistemas, freqüentemente, falhava em servir seus públicos.

Martinez-Silveira e Oddone (2007) observam até a década de 1980 diversos estudos centrados nos sistemas de informação e em sua eficácia, em vista ao perfeito funcionamento do sistema num todo e de seus mecanismos de recuperação da informação. A partir da década de 1980 os estudos começam a perceber o usuário como centro das atividades, ocorre uma mudança em relação à abordagem centrada no sistema para uma abordagem centrada no usuário, em grande parte devido à automação das tarefas documentárias.

A abordagem "centrada no usuário" (tradução de person-centred ou user-centered) (WILSON, 2000), ou "orientada ao usuário" (tradução de user-oriented) (BATES, 2010) parte de uma perspectiva psicológica do sujeito, das interferências ou influências que os atributos individuais e as motivações psicológicas exercem no comportamento informacional.

De acordo com Miranda (2007, p. 99), as revisões do Annual Review of Information Science and Technology (ARIST) apontaram que até 1986 havia uma falta de refinamento conceitual e metodológico nos estudos das necessidades e usos de informação, "[...] bem como pouca consideração sobre o ambiente de uso da informação e sobre a distinção entre os aspectos cognitivos e sociais da informação". Posteriormente a esse período, as revisões do ARIST "[...] identificaram uma mudança de paradigma na área e o aparecimento de estudos que consideravam o usuário como ponto central de análise, e não os sistemas de informação" (MIRANDA, 2007, p. 100). Wilson (2000) acrescenta que, além da mudança do foco central da abordagem, ocorreu de forma conjunta a mudança do uso de métodos quantitativos para métodos qualitativos.

Bates (2010) observa que durante os anos de 1990 pesquisadores de recuperação da informação, que até o momento eram céticos em relação às questões humanas envolvidas no processo de recuperação da informação passam a perceber a necessidade do lado humano para melhorias no processo.

A nomenclatura "comportamento informacional" veio a ser introduzida e utilizada amplamente para substituir os termos "busca", "uso" e "necessidades" de informação. Sua adequação tem início no final da década de 1990, nas publicações de Tom D. Wilson, que argumenta a ampliação do campo de estudos, e a necessidade de incluir conceitos sobre necessidade e oferta da informação (BATES, 2010; GASQUE; COSTA, 2010). 
Devido à amplitude de campos científicos empenhados em pesquisas de comportamento informacional, e pela diversidade de definições para a nomenclatura e seus termos correlatos, Wilson (2000) propôs quatro definições:

1. comportamento informacional: a totalidade do comportamento humano em relação ao uso de fontes e canais de informação, incluindo a busca da informação passiva ou ativa;

2. comportamento de busca da informação: a atividade ou ação de buscar informação em conseqüência da necessidade de atingir um objetivo;

3. comportamento de pesquisa da informação: o nível micro do comportamento, em que o indivíduo interage com sistemas de informação de todos os tipos; e

4. comportamento de uso da informação: constitui o conjunto dos atos físicos e mentais, e envolve a incorporação da nova informação aos conhecimentos prévios do indivíduo.

Segundo Gasque e Costa (2010) os argumentos contrários em relação à nomenclatura 'comportamento informacional' amparavam-se na associação inapropriada do termo 'comportamento' ao paradigma behaviorista ou comportamentalista da psicologia, bem como pela inadequação semântica dos termos que se justifica pelo fato da informação não possuir comportamento.

Bates (2010, p. 2381) considera duas perspectivas para a nomenclatura 'comportamento informacional', a primeira, define-a como "[...] termo preferido usado para descrever as diversas formas que os seres humanos interagem com a informação, em particular, as formas que as pessoas buscam e usam a informação." A segunda, referente à "[...] uma sub-disciplina da Ciência da Informação e Biblioteconomia que se ocupa de uma ampla gama de tipos de pesquisas conduzidas a fim de entender o relacionamento humano com a informação."

A partir do século XXI uma nova vertente vem-se consolidando, voltada a uma abordagem mais socializante, verificou-se que contextos históricos, sociais e culturais influenciam diretamente no comportamento informacional.

Na década de 1990 e 2000, juntamente com o crescimento da "Comunidade de Busca da Informação em Contexto" (tradução de Information Seeking in Context - ISIC), paralelamente, ocorreu à expansão na perspectiva em comportamento informacional no estudo das interações entre pessoas e informações, incorporando todo o ambiente físico, social e tecnológico. O contexto e a situação passam a ser reconhecidos como fundamentais para o entendimento da busca da informação (COOL, 2001; COURTRIGHT, 2007 apud BATES, 2010).

A consolidação desta nova vertente nos estudos comportamentais de informação é reconhecida na forma da ISIC, que teve início no ano de 1996 em Tampere (Finlândia), sendo posteriormente apresentada bienalmente, principalmente na Europa.

Os pesquisadores que seguem esta vertente têm argumentado que o estudo do comportamento informacional deve ir além dos projetos tradicionais de pesquisa, e justificam que o contexto precisa ser entendido num sentido mais amplo. $\mathrm{O}$ argumento formulasse em estudos qualitativos mais ricos e detalhados de situações e contextos específicos, a fim de, entender as várias formas sutis, em que as pessoas recebem e modelam a informação (BATES, 2010).

Martínez-Silveira e Oddone (2007, p. 118) observam que, "[...] a perspectiva de estudo é a de que este contexto desempenha papel tão importante quanto às estruturas cognitivas individuais ou as características mecânicas e operacionais dos sistemas de informação."

Segundo Araújo (2008), o elemento social como traço identificador começa a ser consolidado no início da década de 1970, e especialmente na década de 1980, em que os interesses de pesquisa começam progressivamente direcionar-se ao próprio usuário, suas necessidades e interação com a informação.

Nas abordagens centradas no usuário, em geral, é atribuído ao sujeito papel fundamental de significação da informação e na construção de conhecimento, desenvolvendo-se diferentes perspectivas de abordagem do comportamento informacional sem desconsiderar variáveis contextuais, cognitivas, emocionais, afetivas entre outras. De acordo com Fidel et al. (2004, p. 952) "[...] a interação homem-informação é um fenômeno complexo e requer análises complexas." 
Fidel et al. (2004) argumentam que a maioria das pesquisas que tratam de comportamento informacional têm-se concentrado numa única dimensão - ou na psicológica ou na social - ademais, poucos pesquisadores têm considerado ambas num único estudo. Dessa forma, o estudo do comportamento informacional pode ser observado a partir de duas principais abordagens, conforme mostra a figura 1.

Figura 1 - Abordagens nos estudos de Comportamento Informacional.

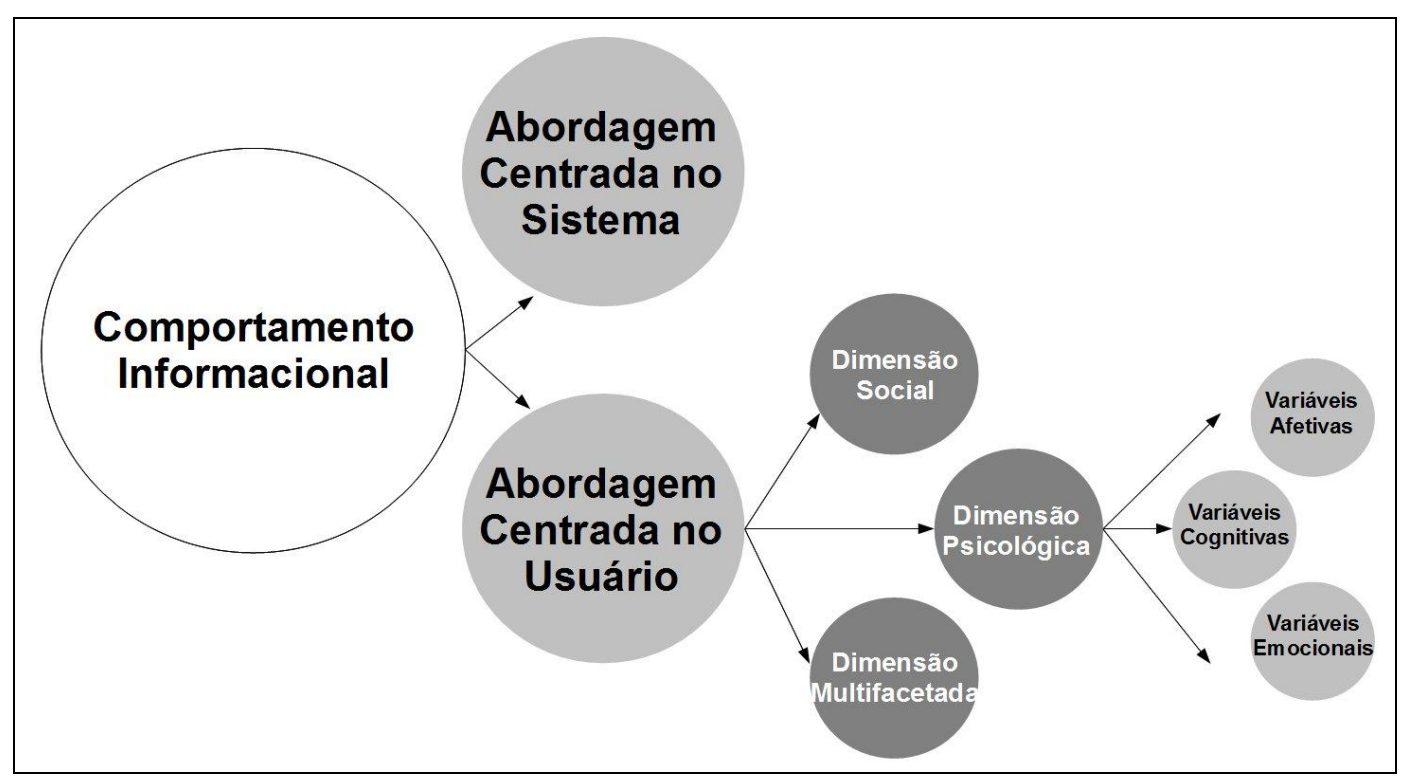

Fonte: Baseado em Fidel et al. (2004).

$\mathrm{Na}$ abordagem centrada no sistema, o foco direciona-se ao funcionamento do sistema de informação, que é estabelecido pela concordância entre a consulta realizada e o resultado obtido. Marchionini (1997) considera que uma máquina não pode empreender uma busca informacional, somente sendo capaz de recuperar informação, no sentido mecânico de entrada e resposta, sendo o comportamento informacional conduzido somente pelos seres humanos.

Enquanto nas abordagens centradas no usuário podem ser enfatizados certos aspectos de natureza psicológica, social ou ambas. A abordagem psicológica tem foco primariamente no estudo dos estados e processos psicológicos em relação ao comportamento informacional (cognitivo, afetivo, emocional). O núcleo da dimensão psicológica é o conceito de necessidade informacional.

Fidel et al. (2004, p. 940) citam que os estudos quando focados no comportamento de busca, as variáveis comumente convergem para a dimensão psicológica, visto que, "são expressas em ótimo detalhe e a nível mensurável (ex.: nível de entendimento da estrutura de uma base de dados, variedade cognitiva, número de erros)." $\mathrm{Na}$ abordagem social, o comportamento informacional independe de atributos psicológicos, seu foco são os efeitos do contextos social no comportamento, suas variáveis são expressas num plano geral (ex.: contexto, experiência cultural, redes sociais).

A abordagem multifacetada ou multidimensional foca um grupo específico de pessoas em certo contexto, freqüentemente realizando uma tarefa particular e considera de forma integrada variáveis relativas tanto ao contexto social quanto aos aspectos psicológicos (FIDEL et al., 2004).

De acordo com Fidel et al. (2004, p. 940) a abordagem prevalecente entre pesquisadores em comportamento informacional é a psicológica, com enfoque maior nos aspectos cognitivos e menor nos outros. Os autores argumentam esse cenário é decorrência do "[...] campo ainda não estar preparado para expressar variáveis provenientes de outras dimensões num determinado nível de mensuração." Justificam ainda, pela própria inconsistência no conceito de informação. 


\section{Resultados}

A pesquisa caracteriza-se como documental, com tratamento e análise dos dados de forma exploratória e descritiva. Para a investigação foram escolhidas as teses e dissertações na área de Ciência da Informação no Brasil defendidas no período de 2007 a abril de 2012 que abordaram a temática de comportamento informacional, a princípio, foram identificados os Programas de Pós-Graduação em Ciência da Informação no Brasil e as respectivas Universidades, conforme quadro 1, a partir do resultado da Avaliação Trienal de Programas de Pós-Graduação da CAPES (2007-2009) de 2010. No Brasil, desde 2006 a CAPES (2006) solicita que os respectivos programas divulguem suas produções de pesquisa.

Quadro 1: Universidades brasileiras que oferecem Pós-Graduação stricto sensu em Ciência da Informação.

\begin{tabular}{|l|l|}
\hline Universidade Federal da Bahia (UFBA) & Universidade Federal de Pernambuco (UFPE) \\
\hline Universidade Federal da Paraíba (UFPB) & Universidade de Brasília (UNB) \\
\hline Universidade Federal do Rio de Janeiro (UFRJ) & Universidade Federal Fluminense (UFF) \\
\hline Universidade de São Paulo (USP) & Universidade do Estado de São Paulo (UNESP) \\
\hline Universidade Federal de Minas Gerais (UFMG) & Universidade Federal de Santa Catarina (UFSC) \\
\hline Universidade Estadual de Londrina (UEL) & \\
\hline
\end{tabular}

Fonte: Resultado da Avaliação Trienal de Programas de Pós-Graduação da CAPES (2007-2009).

Para o levantamento de dados foram verificadas as listagens de dissertações (D) e teses (T) defendidas a partir dos sítios eletrônicos de cada Programa de Pós-Graduação stricto sensu. Foi identificado um total de 465 dissertações e 157 teses defendidas entre o período de 2007 a abril de 2012 (tabela 1).

Constatou-se que 56 dissertações e 25 teses encontravam-se indisponíveis, o que impossibilitou a verificação das palavras-chave utilizadas, sendo descartadas para a composição do universo da análise. 
Tabela 1: Teses e dissertações defendidas em Ciência da Informação no Brasil (2007- abril de 2012).

\begin{tabular}{|c|c|c|c|c|c|c|c|c|c|c|c|c|c|c|}
\hline \multirow[t]{2}{*}{ IES } & \multicolumn{2}{|c|}{2007} & \multicolumn{2}{|c|}{2008} & \multicolumn{2}{|c|}{2009} & \multicolumn{2}{|c|}{2010} & \multicolumn{2}{|c|}{2011} & \multicolumn{2}{|c|}{2012} & \multicolumn{2}{|c|}{ Total } \\
\hline & $\mathrm{D}$ & $\mathrm{T}$ & $\mathrm{D}$ & $\mathrm{T}$ & $\mathrm{D}$ & $\mathrm{T}$ & D & $\mathrm{T}$ & D & $\mathrm{T}$ & $\mathrm{D}$ & $\mathrm{T}$ & D & $\mathrm{T}$ \\
\hline UFMG & 21 & 07 & 25 & 10 & 20 & 08 & 18 & 05 & 16 & 13 & 03 & 05 & 103 & 48 \\
\hline USP & 06 & 08 & 05 & 06 & 14 & 03 & 10 & 12 & - & 02 & - & - & 35 & 31 \\
\hline UNB & 22 & 04 & 18 & 10 & 12 & 08 & 12 & 07 & - & 01 & - & - & 64 & 30 \\
\hline UNESP & 06 & 01 & 15 & 04 & 12 & 10 & 15 & 10 & 07 & 03 & - & 02 & 19 & 30 \\
\hline UFRJ & 12 & - & 10 & 04 & 09 & 06 & - & 05 & 19 & 03 & - & - & 50 & 18 \\
\hline UFSC & 11 & - & 08 & - & 13 & - & 13 & - & 12 & - & 03 & - & 60 & - \\
\hline UFPB & - & - & 06 & - & 10 & - & 14 & - & 10 & - & - & - & 40 & - \\
\hline UFBA & 08 & - & 13 & - & 13 & - & 13 & - & - & - & - & - & 39 & - \\
\hline UEL & - & - & - & - & - & - & 10 & - & 22 & - & - & - & 32 & - \\
\hline UFF & - & - & - & - & - & - & - & - & 14 & - & - & - & 14 & - \\
\hline UFPE & - & - & - & - & - & - & - & - & 09 & - & - & - & 09 & - \\
\hline Total & 86 & 20 & 100 & 34 & 103 & 35 & 105 & 39 & 109 & 22 & 06 & 07 & 465 & 157 \\
\hline
\end{tabular}

Fonte: Dados da pesquisa (2012).

A análise dos termos nos documentos teve como base as meta-informações disponíveis nos sítios eletrônicos dos Programas de Pós-Graduação, repositórios institucionais ou bibliotecas digitais das universidades mantenedoras, ou ainda, a partir das palavras-chave no próprio documento. Foram verificados quais documentos continham termos relativos à temática comportamento informacional no título e/ou nas palavras-chave, listados no quadro 2. Os termos considerados para a seleção das teses e dissertações foram estabelecidos mediante a freqüência de uso e co-relação na literatura referente à temática.

Quadro 2: Termos selecionados para o levantamento das teses e dissertações em relação a Comportamento Informacional.

\begin{tabular}{|l|l|l|}
\hline Comportamento Informacional & (Comportamento) de uso da informação & Estudo de Usuários \\
\hline $\begin{array}{l}\text { (Comportamento) de Busca da } \\
\text { Informação }\end{array}$ & Acesso à informação & Tomada de decisão \\
\hline $\begin{array}{l}\text { (Comportamento) de Pesquisa da } \\
\text { Informação }\end{array}$ & Necessidade de Informação & Recuperação da Informação \\
\hline
\end{tabular}

Fonte: Dados da pesquisa (2012). 
Durante a verificação das teses e dissertações identificou-se o uso predominante de alguns termos, de sinônimos e co-relatos aos termos estabelecidos, por exemplo: "(Ontologias) recuperação da informação" e "sistema de recuperação da informação" para Recuperação da Informação, "processo decisório" para Tomada de Decisão, e "demanda de informação" para Necessidade de Informação. Constatada estas ocorrências, a título de análise, foram estabelecidos 11 termos principais (quadro 3), nos quais os termos sinônimos e co-relatos foram agrupados com os respectivos termos afins, e mantidos os termos predominantes.

Encontrou-se com freqüência a associação dos termos Necessidade, Busca, e Acesso com o termo Uso da informação, nestes casos, foram reunidos num único grupo, denominado: Necessidade, Busca, Acesso e Uso da Informação (NBAU). As siglas designadas para cada grupo serão utilizadas no decorrer da apresentação dos dados da presente pesquisa.

\section{Quadro 3: Termos e siglas estabelecidas para o direcionamento da análise dos dados.}

\begin{tabular}{|l|l|l|}
\hline Comportamento Informacional (Cl) & Busca da Informação (BI); & Sense-Making (SM) \\
\hline $\begin{array}{l}\text { Comportamento de Busca da } \\
\text { Informação (CBI); }\end{array}$ & Acesso à informação (Al); & Tomada de decisão (TD); e \\
\hline Necessidade de Informação (NI) & Uso da Informação (UI); & Recuperação da Informação (RI). \\
\hline Estudo de Usuários (EU); & $\begin{array}{l}\text { Necessidade, Busca, Acesso e Uso } \\
\text { da Informação (NBAU) }\end{array}$ & \\
\hline
\end{tabular}

Fonte: Dados da pesquisa (2012).

Mediantes estes termos, foi constatado um universo de análise composto de 88 dissertações e 17 teses, apresentado na tabela 2 dispõe a quantidade de dissertações e teses que continham pelo menos um dos termos estabelecidos, no título e/ou entre as palavras-chave, organizados conforme 0 ano de defesa e a instituição de ensino superior.

Tabela 2: Teses e dissertações relacionadas a Comportamento Informacional.

\begin{tabular}{|c|c|c|c|c|c|c|c|c|c|c|c|c|c|c|}
\hline \multirow{2}{*}{ IES / Ano } & \multicolumn{2}{|c|}{2007} & \multicolumn{2}{|c|}{2008} & \multicolumn{2}{|c|}{2009} & \multicolumn{2}{|c|}{2010} & \multicolumn{2}{|c|}{2011} & \multicolumn{2}{|c|}{2012} & \multicolumn{2}{|c|}{ Total } \\
\hline UFMG & 03 & 02 & 07 & 04 & 05 & NE & 03 & 02 & 03 & NE & NE & NE & 21 & 08 \\
\hline UNB & 06 & 01 & 04 & 02 & 04 & 01 & 02 & 01 & - & NE & - & - & 16 & 05 \\
\hline UNESP & 02 & NE & 03 & NE & 02 & 01 & 02 & NE & 02 & NE & - & 01 & 11 & 02 \\
\hline USP & 02 & 01 & NE & NE & 01 & NE & 01 & NE & - & NE & - & - & 04 & 01 \\
\hline UFF & 01 & - & 01 & 01 & - & - & - & - & 01 & - & - & - & 03 & 01 \\
\hline UFRJ & NE & - & NE & NE & NE & NE & - & NE & 05 & NE & - & - & 05 & NE \\
\hline UFBA & 01 & - & 03 & - & 03 & - & 01 & - & - & - & - & - & 08 & - \\
\hline UFSC & 02 & - & 02 & - & 01 & - & 02 & - & 01 & - & 01 & - & 09 & - \\
\hline
\end{tabular}




\begin{tabular}{|c|c|c|c|c|c|c|c|c|c|c|c|c|c|}
\hline UFPB & - & - & 02 & - & 02 & - & 03 & - & 01 & - & - & - & 08 \\
\hline UEL & - & - & - & - & - & - & 04 & - & NE & - & - & - & 04 \\
\hline UFPE & - & - & - & - & - & - & - & - & NE & - & - & - & NE \\
\hline Total & 17 & 04 & 22 & 07 & 18 & 02 & 18 & 03 & 13 & NE & 01 & 01 & $\mathbf{8 8}$ \\
\hline
\end{tabular}

Fonte: Dados da pesquisa (2012).

Legenda: NE (não encontrado) significa que nos respectivos programas de pós-graduação teve documentos publicados mas não foram relacionados aos termos da pesquisa (seja nos títulos e nas palavras-chaves)

Entre as teses e dissertações verificadas na UFRJ, constatou-se dupla institucionalidade de duas dissertações e uma tese, defendidas nos anos de 2007, 2008 e 2007, respectivamente. Disponibilizadas na UFRJ, no entanto, pertencentes à UFF. Nestes casos, consideramos os três trabalhos relativos à UFF.

Detalhadamente observa-se que na UFMG foram 29 trabalhos: Campos (2007), Costa (2007), Nadaes (2007), Pinto (2007), Venâncio (2007), Adão (2008), Andrade (2008), Brum (2008), Grossi (2008), Leal (2008), Maia (2008), Mattos (2008), Oliveira (2008), Pereira (2008), Rabelo (2008), Silva (2008), Aguiar (2009), Caixeta (2009), Nonatto (2009), Oliveira (2009), Teixeira (2009), Aganette (2010), Ferreira (2010), Ladeira (2010), Leitão (2010), Pessoa (2010), Demarques (2011), Maculan (2011), e Pereira (2011).

Na UNB foram 21 trabalhos: Câmara Júnior (2007), Caselli (2007), Fauat (2007), Marques (2007), Matta (2007), Miranda (2007), Santos (2007), Carvalho (2008), Cruz, F. L. (2008), CRUZ, F. W. (2008), Feitosa (2008), Gasque (2008), Oliveira (2008), Barreto (2009), Brandt (2009), Costa (2009), Rodrigues (2009), Santos (2009), Neto (2010), Simão (2010), e Teixeira (2010).

Na UNESP foram 13 trabalhos: Euclides (2007), Garcia (2007), Banhos (2008), Coneglian (2008), Santos (2008), Boccato (2009), Guerrero (2009), Xavier (2009), Cavalcante (2010), Silva (2010), Gama (2011), Lousada (2011), Matta (2012).

Na USP foram cinco (5) trabalhos: Matos (2007), Reis (2007), Silva (2007), Sousa (2009), Gonçalves (2010).

Na UFF foram quatro (4) trabalhos: Velho (2007), Delaia (2008), Ribeiro (2008), Barçante (2011)

$\mathrm{Na}$ UFRJ foram cinco (5) trabalhos: Almeida (2011), Barros (2011), Botão (2011), Figueiredo (2011), e Giordano (2011).

Na UFBA foram oito (8) trabalhos: Amaral (2007), Oliveira (2008), Peres (2008), Velasco (2008), Marques (2009), Oliveira (2009), Santana (2009), e Zaidan (2010).

Na UFSC foram nove (9) trabalhos: Bedin (2007), Dávilla Calle (2008), Floriani (2007), Molossi (2008), Abe (2009), Alvorcem (2010), Wensig (2010), Fazzioni (2011), e Barros (2012).

Na UFPB foram oito (8) trabalhos: Costa (2008), Silva (2008), Barros (2009), Lima (2009), Duarte (2010), Maciel Albuquerque (2010), Sales (2010), e Santiago (2011).

Na UEL foram quatro (4) trabalhos: Amorim (2010), Csiszer (2010), Gomes (2010), e Nishitani (2010).

Na UFPE não foram encontrados trabalhos desta abordagem.

Com base nesse universo, foi verificada a freqüência de uso dos termos nos títulos e palavras-chave das teses e dissertações em cada ano e por cada termo, exibidos na figura 2. Foram atribuídas cores diferentes para os termos, sendo as teses destacadas por cores mais acentuadas. 
Figura 2: Relação das ocorrências de uso dos termos no título e nas palavras-chave das Teses e Dissertações.

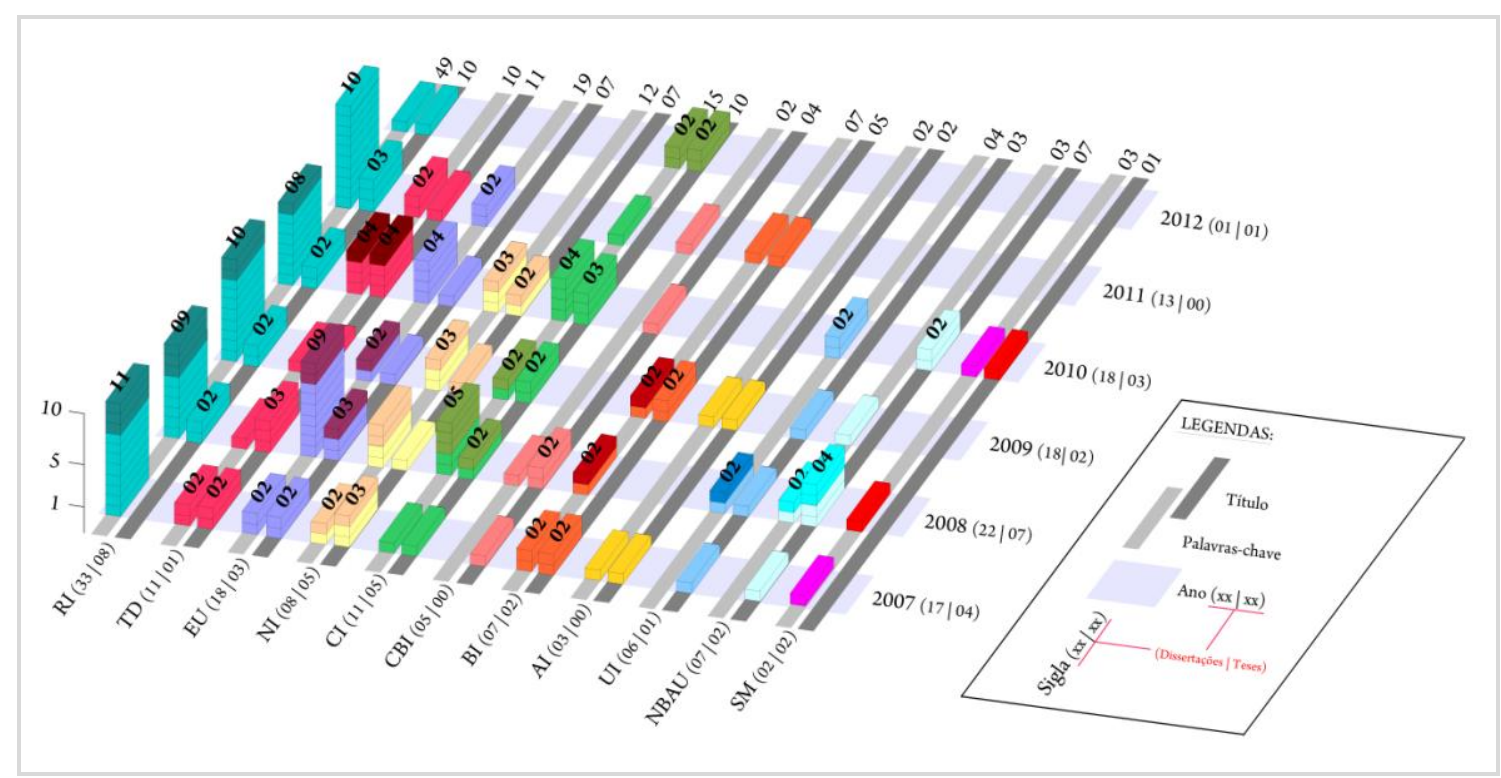

Fonte: Dados da pesquisa (2012).

Identificou-se a ausência, duplicidade e multiplicidade dos termos nos documentos analisados, isto é, em alguns documentos o termo aparecia no título, no entanto não aparecia entre as palavras-chave, ou aparecia tanto no título como nas palavras, ou ainda, aparecia mais de um dos termos no título ou nas palavras-chave. Os termos que apareceram com maior freqüência no título foram: Tomada de Decisão (11), Comportamento Informacional (10) e Recuperação da Informação (10). Cabe salientar que, nas palavras-chave a Recuperação da Informação (49) teve a maior freqüência de ocorrência entre os termos, seguida de Estudo de Usuários (19), Comportamento informacional (15), Necessidade de Informação (12), e Tomada de Decisão (10). Observasse uma média de 19 documentos por ano nos documentos analisado entre 2007 e 2010.

Por intermédio da ocorrência dos termos nos títulos e palavras-chave das teses e dissertações, bem como os respectivos orientadores, criou-se um grafo para exibir a freqüência de uso dos termos, a associação entre eles, bem como a associação e distribuição dos orientadores com os termos, exposto na figura 3. 


\section{Figura 3: Grafo de Distribuição de orientadores pelos temas.}

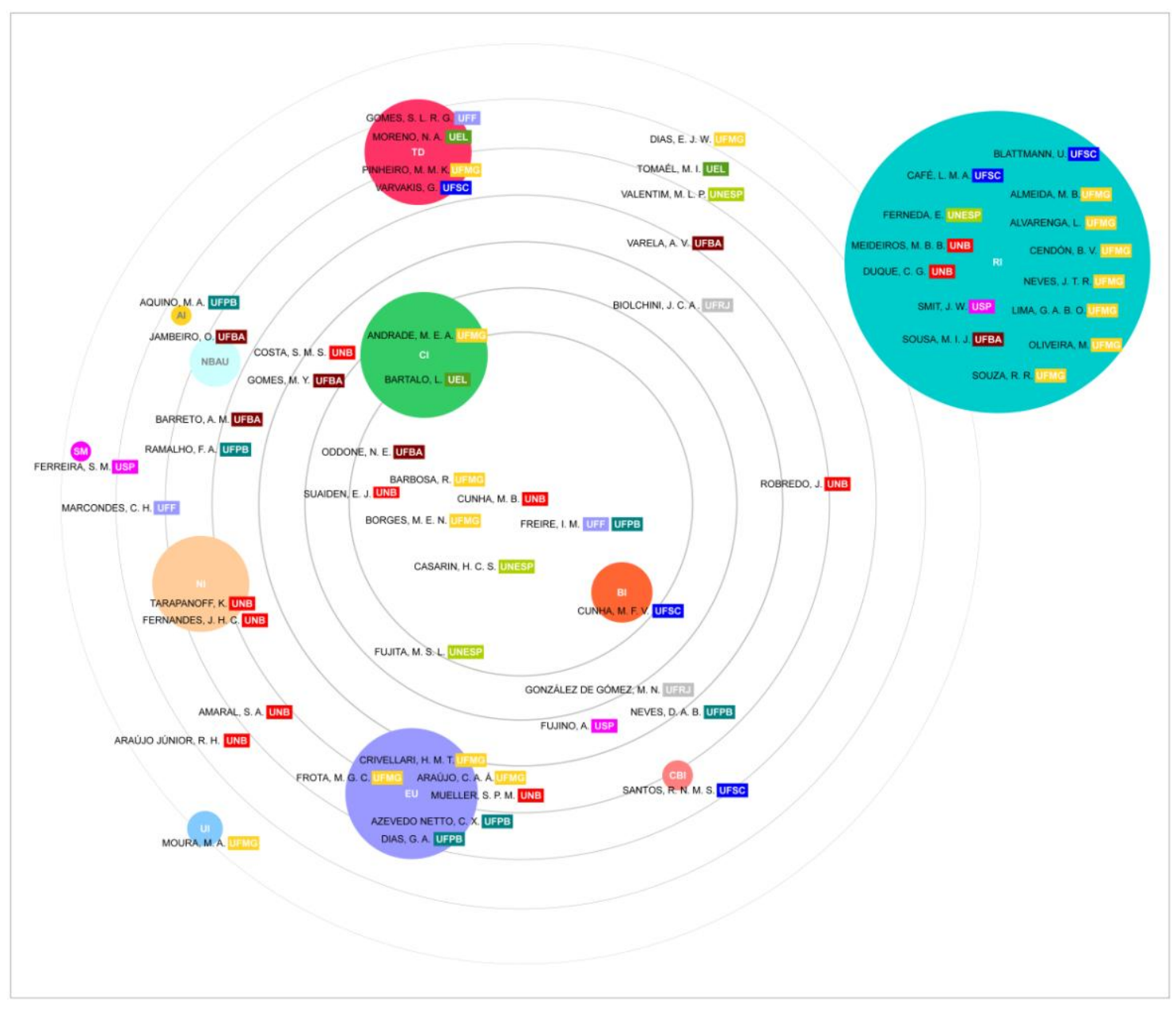

Fonte: Dados da pesquisa (2012).

O grafo demonstra as redes terminológicas e as relações proximais e distanciais entre os termos, bem como dos orientadores e instituições de ensino superior que tem trabalhado com a temática de comportamento informacional no Brasil. Observasse que, apesar do termo Recuperação da Informação ter um índice alto de ocorrência nos documentos ele tem pouca afinidade com os demais termos. Os termos Comportamento Informacional, Necessidade de Informação, Busca de Informação e Estudo de Usuários conferem as extremidades do núcleo temático, enquanto que, os demais termos demonstram-se orbitais a esses quatro.

Nota-se que os orientadores da temática de Recuperação da Informação se encontram tematicamente mais homogêneos e consolidados, enquanto que, os orientadores dos temas confluentes a comportamento informacional se encontram dispersos e heterogêneos entre os termos afins, apesar do consenso parcial em relação aos termos pertinentes ao estudo da temática comportamento informacional, não há um termo representativamente unânime. Somente nos casos dos termos Tomada de Decisão e Estudo de Usuários observasse uma estabilidade maior, que pode ser apurada com maior detalhe na Figura 2. Como foi apontado anteriormente, o termo Tomada de Decisão foi o mais citado nos títulos dos trabalhos, e Estudo de Usuários o segundo mais citado nas palavras-chave, ficando abaixo somente de Recuperação da Informação.

Verificasse o posicionamento central de seis orientadores no grafo, são eles: Ricardo Barbosa (UFMG), Mônica Erichsen Nassif Borges (UFMG), Murilo Bastos da Cunha (UNB), Emir José Suaiden (UNB), Helen de Castro 
Silva Casarin (UNESP), Isa Maria Freire (UFF / UFPB). No caso da Isa Maria Freire, a mesma aparece com dupla institucionalidade, devido a sua transferência da UFF para a UFPB durante o período analisado pela presente pesquisada. Ao se observar o "cardume", isto é, a afluência de orientados no grafo verificasse que as IES dos seis orientadores centrais da temática comportamento informacional aparecem com maior freqüência, são elas: UFMG, UNB, UNESP e UFPB.

$\mathrm{Na}$ criação do grafo foram privilegiados apenas os termos utilizados nos títulos e palavras-chave das teses e dissertações analisadas. Cabe mencionar que outras representações visuais poderiam ser realizadas, como no caso do termo recuperação da informação, que teria uma subdivisão entre sistemas computacionais e de organização da informação (terminologia).

\section{Conclusões}

O estudo aponta continuidade nas pesquisas publicadas sobre comportamento informacional nos programas de pós-graduação em Ciência da Informação no Brasil. Aparece um núcleo de instituições e de orientadores situados em UFMG, UNB, UNESP e UFPB.

A repercussão dos estudos de comportamento informacional na Ciência da Informação apresentaram relações entre os termos, aproximidades e um distanciamento terminológico com a recuperação da informação no contexto da pesquisa.

Para estudos futuros, recomendamos a realização deste estudo entre as publicações científicas (periódicos, anais, livros) em relação a comportamento informacional na área de Ciência da Informação e em outras áreas do conhecimento, com o intuito traçar um panorama da temática e demonstrar a relação entre os termos e assuntos, os orientadores ou pesquisadores que tem investigado sobre o assunto, além de identificar as instituições de ensino superior que tem acolhido interesse em pesquisas relativas ao comportamento informacional. Estudos irrestritos ao território nacional, expandido para outros países e criando um mapa global da temática.

Sugere-se estudos para enfocar a análise de conteúdo dessas teses e dissertações referentes ao comportamento informacional, a fim de investigar quais os tipos de pesquisas, as diferentes metodologias, os fundamentos teóricos e aplicados utilizados em estudos de comportamento informacional, para ampliar os direcionamentos da temática. 


\section{Referências}

ARAUJO, Carlos Alberto Ávila. Estudos de usuários: pluralidade teórica, diversidade de objetos. In: Encontro Nacional de Pesquisa em Ciência da Informação- ENANCIB, 9, 2008, São Paulo, Anais eletrônicos... Disponível em:

<http://bogliolo.eci.ufmg.br/downloads/ARAUJO\%20Enancib\%202008.pdf> Acesso em: 24 maio 2010.

BATES, Marcia J. Information Behavior. In: BATES, Marcia J.; MAACK, Mary Niles (Org.). Encyclopedia of Library and Information Sciences, 3ed., New York, NY: CRC Press, v. 3, p. 2347-2360, 2010. Disponível em:

<http://gseis.ucla.edu/faculty/bates/articles/information-behavior.html>. Acesso em: 17 fev. 2011.

BELKIN, N. Anomalous states of knowledge as a basis for information retrieval. Canadian Journal of Information Science, v. 5, p. 133-143, 1980.

CASE, Donald O. Looking for Information: A survey of research on information seeking, needs, and behavior. 2 ed. Academic Press: San Diego, 2002.

COORDENAÇÃO DE APERFEIÇOAMENTO DE PESSOAL DE NÍVEL SUPERIOR - CAPES. Relatório de Avaliação 2007-2009

(Trienal 2010) - Área de Avaliação: Ciências Sociais Aplicadas I. Disponível em: <http://trienal.capes.gov.br/wpcontent/uploads/2010/09/Cl\%C3\%8ANCIAS-SOCIAIS-ALICADAS-I-rel-11set10.pdf>. Acesso em: 10 dez. 2010.

COORDENAÇÃO DE APERFEIÇOAMENTO DE PESSOAL DE NÍVEL SUPERIOR (CAPES). Avaliação da pós-graduação. 2012. Disponível em: <http://capes.gov.br/avaliacao/avaliacao-da-pos-graduacao>. Acesso em: 18 maio de 2012.

COORDENAÇÃO DE APERFEIÇOAMENTO DE PESSOAL DE NÍVEL SUPERIOR - CAPES. Portaria $\mathbf{n}^{\circ} \mathbf{1 3}$, de fevereiro de 2006. Disponível em: <http://www.eceme.ensino.eb.br/portalcee/arquivos/Port013 15fev05.pdf>. Acesso em: 08 dez. 2010.

CRESPO, Isabel Merlo; CAREGNATO, Sônia Elisa. Padrões de comportamento de busca e uso de informação por pesquisadores de biologia molecular e biotecnologia. Ciência da Informação, v. 35, n. 3, p. 30-38, set./dez. 2006. Disponível em: <http://revista.ibict.br/index.php/ciinf/article/download/784/641>. Acesso em: 07 dez. 2010.

DERVIN, Brenda L. From the mind1s eye of the user?: the sense-making qualitative-quantitative methodology. In: Glazier, J. D.; POWELL, R. R. Qualitative research in information management. Englewood: Libraries Unlimited, 1992. p. 61-84.

DERVIN, Brenda. An overview of Sense-Making research: Concepts, methods, and resultads to date. In: Annual Meeting of the International Communication Association, Dallas, TX, maio 1983. Acesso em: 20 jul. 2011. Disponível em: <http://www.ideals.illinois.edu/bitstream/handle/2142/2281/Dervin83a.htm>. Acesso em: 20 jul. 2011.

FIDEL, Raya et al. A Multidimensional Approach to the Study of Human-Information Interaction: A Case of Collaborative Information Retrieval. Journal of the American Society for Information Science and Technology, v. 55, n. 11, p. 939-953, 2004. Disponível em: <http://onlinelibrary.wiley.com/doi/10.1002/asi.20041/pdf>. Acesso em: 07 dez. 2010.

FIDEL, Raya ; PEJTERSEN, Annelise. From information behaviour research to the design of information systems: the Cognitive Work Analysis framework. Information Research, v. 10, n. 1, out. 2004. Disponível em: <http://informationr. net/ir/101/paper210.html>. Acesso em: 15 ju. 2011.

GASQUE, Kelley C.; COSTA, Sely M. Evolução teórico-metodológica dos estudos de comportamento informacional de usuários. Ciência da Informação, v. 39, n. 1 p. 21-32, jan./abr. 2010. Disponível em: <http://revista.ibict.br/index.php/ciinf/article/download/1206/1355>. Acesso em: 17 fev. 2011.

HERNÁNDEZ SALAZAR, Patricia et al. Análisis de modelos de comportamiento em la búsqueda de información. Ciência da Informação, v. 36, n. 1, p. 136-146, jan./abr. 2007. Disponível em: <http://www.brapci.ufpr.br/download.php?dd0=6858>. Acesso em: 07 dez. 2010.

KUHLTHAU, Carol C. Inside the Search Process: Information Seeking from the User's Perspective. Journal of the American Society for Information Science, v. 42, n. 5, p. 361-371, 1991. Disponível em:

<http://bogliolo.eci.ufmg.br/downloads/kuhlthau.pdf>. Acesso em: 27 jul. 2011.

MARCHIONINI, Gary. Information Seeking in Electronic Environments. New York: Cambridge University Press. 1997. Disponível em: <http://www.ils.unc.edu/ march/isee book/web page.html>. Acesso em: 08 dez. 2010.

MARTÍNEZ-SILVEIRA, Martha; ODDONE, Nanci. Necessidades e comportamento informacional: conceituação e modelos. Ciência da Informação, v. 36, n. 1, p. 118-127, maio/ago. 2007. Disponível em: <http://revista.ibict.br/index.php/ciinf/article/view/797/725>. Acesso em: 07 dez. 2010. 
MIRANDA, Silvânia Vieira de. Identificação de necessidades de informação e sua relação com competências informacionais: o caso da Supervisão Indireta de Instituições Financeiras no Brasil. 2007. 293 f. Tese (Doutorado) - Faculdade de Economia, Administração, Contabilidade e Ciência da Informação e Documentação, Departamento de Ciência da Informação e Documentação, Universidade de Brasília, Brasília (DF), 2007. Disponível em: <http://repositorio.bce.unb.br/bitstream/10482/2903/1/2007 SilvaniaVieiradeMiranda.pdf>. Acesso em: 07 dez. 2010.

TAYLOR, Robert. Question-Negotiation and Information-Seeking in Libraries. In: Studies in the Man-System Interface in Libraries, Center for the Information Sciences Lehigh University, report n. 3, p. 1-99, ju.1967. Disponível em: <http://www.dtic.mil/cgi-bin/GetTRDoc?AD=AD659468\&Location=U2\&doc=GetTRDoc.pdf >. Acesso em: 27 jul. 2011.

WILSON, Tom D. Human Information Behavior. Information Science Research, v. 3, n. 2, 2000. Disponível em: <http://inform.nu/Articles/Vol3/v3n2p49-56.pdf>. Acesso em: 07 nov. 2010.

WILSON, Tom D. Information Behaviour: an intedisciplinary perspective. Information Processing \& Management, v. 33, n. 4, p. 551-572, 1997. Disponível em: <http://ptarpp2.uitm.edu.my/silibus/infoBehavior.pdf>. Acesso em: 25 ago. 2011.

WILSON, Tom D. Models in information behaviour research. Journal of Documentation, v. 55, n. 3, p. 249-270, 1999. Disponível em: <http://informationr.net/tdw/publ/papers/1999JDoc.html>. Acesso em: 07 dez. 2010.

WILSON, Tom D. On user studies and information needs. Journal of Documentation, v. 37, n. 1, p. 3-15, 1981.

XIE, Hong Iris. Interactive Information Retrieval in Digital Environments. Hershey : IGI Publishing, 2008.

\section{Teses e dissertações consultadas}

\section{UNIVERSIDADE FEDERAL DE MINAS GERAIS - UFMG - Belo Horizonte}

ADÃO, Sheila Margareth Teixeira. Informação para a ação: o uso da informação como suporte às reivindicações sindicais no âmbito da segurança e da saúde do trabalhador. 190 f. Dissertação (Mestrado) - Escola de Ciências da Informação, Universidade Federal de Minas Gerais, 2008. Disponível em: <http://www.bibliotecadigital.ufmg.br/dspace/bitstream/1843/ECID7NRRCP/1/disserta o sheila margareth teixeira.pdf>. Acesso em: 12 de maio de 2012.

AGANETTE, Elisângela Cristina. Taxonomias corporativas: um estudo sobre definições e etapas de construção fundamentado na literatura publicada. 111 f. Dissertação (Mestrado) - Escola de Ciências da Informação, Universidade Federal de Minas Gerais, 2010. Disponível em: <http://www.bibliotecadigital.ufmg.br/dspace/bitstream/1843/ECID-

87BJSR/1/disserta o elis ngela aganette 2010.pdf>. Acesso em: 12 de maio de 2012.

AGUIAR, Cristiana Elisa. Uso de fontes de informação no setor de Previdência Privada aberta no Brasil. 110 f. Dissertação (Mestrado) - Escola de Ciências da Informação, Universidade Federal de Minas Gerais, 2009. Disponível em: $<$ http://www.bibliotecadigital.ufmg.br/dspace/bitstream/1843/ECID$7 \mathrm{~V} 2 \mathrm{GVP} / 1 /$ disserta 0 mestrado cristiana elisa aquiar ribeiro.pdf>. Acesso em: 12 de maio de 2012.

ANDRADE, André Queiroz de. A tomada de decisão e sistemas de informação em saúde. 118 f. Dissertação (Mestrado) Escola de Ciências da Informação, Universidade Federal de Minas Gerais, 2008. Disponível em: <http://www.bibliotecadigital.ufmg.br/dspace/bitstream/1843/ECIC-7XMFGC/1/dissertacao andre queiroz.pdf>. Acesso em: 12 de maio de 2012.

BRUM, Marco Antônio Carvalho. Investigação e análise do comportamento informacional de alunos participantes de empresas juniores no Brasil. 128 f. Dissertação (Mestrado) - Escola de Ciências da Informação, Universidade Federal de Minas Gerais, 2008. Disponível em: <http://www.bibliotecadigital.ufmg.br/dspace/bitstream/1843/ECID-

7NXJGC/1/disserta o marco antonio carvalho brum.pdf>. Acesso em: 12 de maio de 2012.

CAIXETA, Mario Lucio. Processos e comportamentos informacionais em decisões de inovação: o caso do Arranjo Produtivo de Nova Serrana. 213 f. Dissertação (Mestrado) - Escola de Ciências da Informação, Universidade Federal de Minas Gerais, 2009. Disponível em: <http://www.bibliotecadigital.ufmg.br/dspace/bitstream/1843/ECID-7V4PFH/1/dissert mario lucio caixeta.pdf>. Acesso em: 12 de maio de 2012.

CAMPOS, Leonardo Martins. Centrais de Help-Desk: avaliação do serviço de atendimento ao cliente de Empresas Desenvolvedoras de Sistemas de Gestão Empresarial. 237 f. Dissertação (Mestrado) - Escola de Ciências da Informação, Universidade Federal de Minas Gerais, 2007. Disponível em: < http://www.bibliotecadigital.ufmg.br/dspace/bitstream/1843/VALA74QJWH/1/mestrado leonardo martins campos.pdf >. Acesso em: 12 de maio de 2012.

COSTA, Alessandro Ferreira. Gestão arquivística na era do cinema digital: formação de acervos de documentos digitais provindos da prática cinematográfica. 236 f. Tese (Doutorado) - Escola de Ciências da Informação, Universidade Federal de Minas 
Gerais, 2007. Disponível em: <http://www.bibliotecadigital.ufmg.br/dspace/bitstream/1843/VALA74QHGG/1/doutorado alessandro ferreira costa.pdf>. Acesso em: 12 de maio de 2012.

DEMARQUES, Eliana Antônia. Estudo exploratório sobre compatibilização semântica de vocabulário utilizando ontologia: fundamentação teórica-metodológica visando ao aperfeiçoamento do MHTX. 176 f. Dissertação (Mestrado) - Escola de Ciências da Informação, Universidade Federal de Minas Gerais, 2011. Disponível em: $<$ http://www.bibliotecadigital.ufmg.br/dspace/bitstream/1843/ECIC-8KMJTU/1/dissertacaoelianaantoniademarques. pdf > . Acesso em: 12 de maio de 2012.

FERREIRA, Giovanni Estanislau. Avaliação de sistemas de apoio à decisão na perspectiva do usuário da informação: o Data Warehouse como suporte à estratégia organizacional. 145 f. Dissertação (Mestrado) - Escola de Ciências da Informação, Universidade Federal de Minas Gerais, 2010. Disponível em: <http://www.bibliotecadigital.ufmg.br/dspace/bitstream/1843/ECID8AWNXN/1/disserta ao giovanni ferreira 110103.pdf>. Acesso em: 12 de maio de 2012.

GROSSI, Márcia Gorrett Ribeiro. Estudo das características de software e implementação de um software livre para o sistema de gerenciamento de Bibliotecas Universitárias Federais Brasileiras. 253 f. Tese (Doutorado) - Escola de Ciências da Informação, Universidade Federal de Minas Gerais, 2008. Disponível em: <http://www.bibliotecadigital.ufmg.br/dspace/bitstream/1843/EARM-7H8M9J/1/doutorado m rcia gorett ribeiro grossi.pdf>. Acesso em: 12 de maio de 2012.

LADEIRA, Ana Paula. Processamento de linguagem natural: caracterização da produção científica dos pesquisadores brasileiros. 259 f. Tese (Doutorado) - Escola de Ciências da Informação, Universidade Federal de Minas Gerais, 2010. Disponível em: <http://www.bibliotecadigital.ufmg.br/dspace/bitstream/1843/ECID-8B3Q6C/1/tese anapaulaladeira cd.pdf>. Acesso em: 12 de maio de 2012.

LEAL, Rosângela Maria de Almeida Camarano. Contribuições da análise de atividade e da entrevista de autoconfrontação para os estudos de usuários. $171 \mathrm{f}$. Tese (Doutorado) - Escola de Ciências da Informação, Universidade Federal de Minas Gerais, 2008. Disponível em: <http://www.bibliotecadigital.ufmg.br/dspace/bitstream/1843/ECID-

7NRQ4P/1/tese rosangela maria de a. c. leal.pdf >. Acesso em: 12 de maio de 2012.

LEITÃO, Pedro Cláudio Coutinho. Informação, concorrência e processo decisório em Instituições de Ensino Superior: um estudo sob o enfoque do sensemaking organizacional. 179 f. Tese (Doutorado) - Escola de Ciências da Informação, Universidade Federal de Minas Gerais, 2010. Disponível em: <http://www.bibliotecadigital.ufmg.br/dspace/bitstream/1843/ECID8CDJG5/1/tese pedro versao entrega revisado autor 2203 2011.pdf >. Acesso em: 12 de maio de 2012.

MACULAN, Benildes Coura Moreira dos Santos. Taxonomia facetada navegacional: construção a partir de uma matriz categorial para trabalhos acadêmicos. 191 f. Dissertação (Mestrado) - Escola de Ciências da Informação, Universidade Federal de Minas Gerais, 2011. Disponível em: <http://www. bibliotecadigital.ufmg.br/dspace/bitstream/1843/ECID8LAN5K/1/maculan taxonomia facetada navegacional.pdf $>$. Acesso em: 12 de maio de 2012.

MAIA, Luiz Cláudio Gomes. Uso de sintagmas nominais na classificação automática de documentos eletrônicos. 158 f. Tese (Doutorado) - Escola de Ciências da Informação, Universidade Federal de Minas Gerais, 2008. Disponível em: $<$ <ttp://www.bibliotecadigital.ufmg.br/dspace/bitstream/1843/ECID-7NXJKZ/1/tesefinal.pdf>. Acesso em: 12 de maio de 2012.

MATTOS, Ana Maria. Análise de citações de teses como apoio à tomada de decisão no desenvolvimento de coleções de bibliotecas universitárias. 123 f. Dissertação (Mestrado) - Escola de Ciências da Informação, Universidade Federal de Minas Gerais, 2008. Disponível em: <http://www.bibliotecadigital.ufmg.br/dspace/bitstream/1843/ECID-

7NXHSA/1/amm 2008 dissertacao versao eletronica.pdf>. Acesso em: 12 de maio de 2012.

NADAES, Adriana Duarte. Monitoração ambiental no setor de biotecnologia: comportamento de busca e uso de informação em empresas de micro e pequeno portes de Minas Gerais. 144 f. Dissertação (Mestrado) - Escola de Ciências da Informação, Universidade Federal de Minas Gerais, 2007. Disponível em: <http://www.bibliotecadigital.ufmg.br/dspace/bitstream/1843/VALA74QHML/1/mestrado adriana duarte nadaes.pdf>. Acesso em: 12 de maio de 2012.

NONATTO, Rafael dos Santos. Teoria do conceito e hipertextos: uma proposta para determinação de relacionamentos em links conceituais. 122 f. Dissertação (Mestrado) - Escola de Ciências da Informação, Universidade Federal de Minas Gerais, 2009. Disponível em: <http://www.bibliotecadigital.ufmg.br/dspace/bitstream/1843/ECID-7V2GYA/1/dissertacao nonato 2009.pdf>. Acesso em: 12 de maio de 2012.

OLIVEIRA, Carla Cristina Vieira de. A interação dos usuários da UFMG com o catálogo on-line do Sistema Pergamum. $199 \mathrm{f}$. Dissertação (Mestrado) - Escola de Ciências da Informação, Universidade Federal de Minas Gerais, 2008. Disponível em: <http://www.bibliotecadigital.ufmg.br/dspace/bitstream/1843/EARM-7H2Q4E/1/mestrado carla cristina vieira de oliveira.pdf>. Acesso em: 12 de maio de 2012.

OLIVEIRA, Viviane Nogueira Pinto de. Uma investigação sobre a avaliação de modelagem conceitual baseada em ontologias: estudo de caso de modelos para sistemas de informação desenvolvidos na Universidade Federal de Minas Gerais. 177 f. Dissertação (Mestrado) - Escola de Ciências da Informação, Universidade Federal de Minas Gerais, 2009. Disponível em: $<$ <ttp://www.bibliotecadigital.ufmg.br/dspace/bitstream/1843/ECID-7V2JBW/1/disserta o.pdf>. Acesso em: 12 de maio de 2012. 
PEREIRA, Fernanda. Avaliação de usabilidade em bibliotecas digitais: um estudo de caso. $121 \mathrm{f}$. Dissertação (Mestrado) Escola de Ciências da Informação, Universidade Federal de Minas Gerais, 2011. Disponível em: $<$ http://www.bibliotecadigital.ufmg.br/dspace/bitstream/1843/ECID-8LAKHD/1/dissertacao pdf.pdf>. Acesso em: 12 de maio de 2012.

PEREIRA, Julio Cesar Lopes. Necessidades, busca e uso da informação: estudo de caso em um setor de help desk de indústrias cimenteira multinacional. 129 f. Dissertação (Mestrado) - Escola de Ciências da Informação, Universidade Federal de Minas Gerais, 2008. Disponível em: <http://www.bibliotecadigital.ufmg.br/dspace/bitstream/1843/ECID7NXJ9S/1/disserta o vers o final com ficha catalogr fica.pdf>. Acesso em: 12 de maio de 2012.

PESSOA, Marina Torres. A relação entre ouvintes assíduos e o rádio: um estudo de usuários da informação a partir de uma perspectiva compreensiva. 95 f. Dissertação (Mestrado) - Escola de Ciências da Informação, Universidade Federal de Minas Gerais, 2010. Disponível em: <http://www.bibliotecadigital.ufmg.br/dspace/bitstream/1843/ECID87BKB3/1/dissertacaoanexoverdigfinal.pdf>. Acesso em: 12 de maio de 2012.

PINTO, André Moreira. Mineração de textos e gestão do conhecimento: aplicação na experiência operacional em geração de energia nuclear nas Usinas de Angra I e II. 369 f. Tese (Doutorado) - Escola de Ciências da Informação, Universidade Federal de Minas Gerais, 2007. Disponível em: <http://www.bibliotecadigital.ufmg.br/dspace/bitstream/1843/VALA-74QJCX/1/tese 7.00.pdf>. Acesso em: 12 de maio de 2012.

RABELO, Ernane Correa. Comportamento informacional e evocação de notícias: estudo de caso com estudantes de Comunicação Social. 296 f. Tese (Doutorado) - Escola de Ciências da Informação, Universidade Federal de Minas Gerais, 2008. Disponível em: < http://www.bibliotecadigital.ufmg.br/dspace/bitstream/1843/ECID-7NXHFX/1/ppgci ernanerabelo.2008.pdf>. Acesso em: 12 de maio de 2012.

SILVA, Marcos Gomes da. Informação e a população carcerária: estudo de usuários de informação na Penitenciária José Maria Alkmin, Ribeirão das Neves - MG. 142 f. Dissertação (Mestrado) - Escola de Ciências da Informação, Universidade Federal de Minas Gerais, 2008. Disponível em: <http://www.bibliotecadigital.ufmg.br/dspace/bitstream/1843/ECID-7NXJSU/1/marcossilva.pdf>. Acesso em: 12 de maio de 2012.

TEIXEIRA, Livia Marangon Duffles. Conceitualização na construção de ontologias: relações semânticas no âmbito do Blood Project. 201 f. Dissertação (Mestrado) - Escola de Ciências da Informação, Universidade Federal de Minas Gerais, 2009.

Disponível em: <http://www.bibliotecadigital.ufmg.br/dspace/bitstream/1843/ECID-

82AGNQ/1/disserta o entregue livia marangon.pdf>. Acesso em: 12 de maio de 2012.

VENÂNCIO, Ludmila Salomão. O caminhar faz a trilha: o comportamento de busca da informação sob o enfoque da cognição situada. 117 f. Dissertação (Mestrado) - Escola de Ciências da Informação, Universidade Federal de Minas Gerais, 2007. Disponível em: <http://www.bibliotecadigital.ufmg.br/dspace/bitstream/1843/VALA-

74QKJ7/1/mestrado ludmila salom o ven ncio.pdf>. Acesso em: 12 de maio de 2012.

\section{UNIVERSIDADE DE BRASILIA UNB - Brasília Distrito Federal}

BARRETO, Juliano Serra. Anotação automática e recomendação personalizada de documentários brasileiros: sistema DocUnB. 306 f. Dissertação (Mestrado) - Faculdade de Ciência da Informação, Universidade de Brasília, 2009. Disponível em: <http://bdtd.bce.unb.br/tedesimplificado/tde busca/arquivo.php?codArquivo=6811>. Acesso em: 12 de maio de 2012.

BRANDT, Mariana Baptista. Etiquetagem e folksonomia: uma análise sob a óptica dos processos de organização e recuperação da informação na web. 142 f. Dissertação (Mestrado) - Faculdade de Ciência da Informação, Universidade de Brasília, 2009. Disponível em: <http://bdtd.bce.unb.br/tedesimplificado/tde busca/arquivo.php?codArquivo=6259>. Acesso em: 12 de maio de 2012.

CÂMARA JÚNIOR, Auto Tavares da. Indexação automática de acórdãos por meio de processamento de linguagem natural. 141 f. Dissertação (Mestrado) - Faculdade de Ciência da Informação, Universidade de Brasília, 2007. Disponível em: <http://bdtd.bce.unb.br/tedesimplificado/tde busca/arquivo.php?codArquivo=2403>. Acesso em: 12 de maio de 2012.

CARVALHO, Fernanda Cordeiro de. Educação e estudos de usuários em bibliotecas universitárias brasileiras: abordagem centrada nas competências em informação. 145 f. Dissertação (Mestrado) - Faculdade de Ciência da Informação, Universidade de Brasília, 2008. Disponível em:

<http://bdtd.bce.unb.br/tedesimplificado/tde busca/arquivo.php?codArquivo=3388>. Acesso em: 12 de maio de 2012.

CASELLI, Brígida Carla Almeida. Acesso à informação digital por portadores de necessidades especiais visuais: estudo de caso do Telecentro Acessível de Taguatinga. 94 f. Dissertação (Mestrado) - Faculdade de Ciência da Informação, Universidade de Brasília, 2007. Disponível em:

<http://bdtd.bce.unb.br/tedesimplificado/tde busca/arquivo.php?codArquivo=3117>. Acesso em: 12 de maio de 2012.

COSTA, Antônio Marcos Nogueira da Costa. Estudo de usuários como subsídios preliminar à construção de um repositório temático: um estudo de caso aplicado à conscienciologia. 185 f. Dissertação (Mestrado) - Faculdade de Ciência da Informação, 
Universidade de Brasília, 2009. Disponível em:

<http://bdtd.bce.unb.br/tedesimplificado/tde busca/arquivo.php?codArquivo=6591>. Acesso em: 12 de maio de 2012.

CRUZ, Felipe Lopes da. A necessidade de informação dos projetistas de interfaces de sistemas interativos na web, com foco em usabilidade. 104 f. Dissertação (Mestrado) - Faculdade de Ciência da Informação, Universidade de Brasília, 2008. Disponível em: < http://bdtd.bce.unb.br/tedesimplificado/tde busca/arquivo.php?codArquivo=3406>. Acesso em: 12 de maio de 2012.

CRUZ, Fernando William. Necessidades de informação musical de usuários não especializados. 311 f. Tese (Doutorado) Faculdade de Ciência da Informação, Universidade de Brasília, 2008. Disponível em: <http://bdtd.bce.unb.br/tedesimplificado/tde busca/arquivo.php?codArquivo=4312>. Acesso em: 12 de maio de 2012.

FAUAT, Ana Matilde. Comunicação organizacional e padrões de comportamento informacional de gestores e analistas de risco de crédito em instituições financeiras governamentais. 154 f. Dissertação (Mestrado) - Faculdade de Ciência da Informação, Universidade de Brasília, 2007. Disponível em: <http://bdtd.bce.unb.br/tedesimplificado/tde busca/arquivo.php?codArquivo=2518>. Acesso em: 12 de maio de 2012.

FEITOSA, Paula Andréa Cochrane. Divulgação de informação sobre produtos e tecnologias pela Embrapa Hortaliças para os produtores orgânicos de hortaliças. 174 f. Dissertação (Mestrado) - Faculdade de Ciência da Informação, Universidade de Brasília, 2008. Disponível em:

<http://bdtd.bce.unb.br/tedesimplificado/tde busca/arquivo.php?codArquivo=3550>. Acesso em: 12 de maio de 2012.

GASQUE, Kelley Gonçalves Dias. O pensamento reflexivo na busca e no uso da informação na comunicação científica. 241 f. Tese (Doutorado) - Faculdade de Ciência da Informação, Universidade de Brasília, 2008. Disponível em:

<http://bdtd.bce.unb.br/tedesimplificado/tde busca/arquivo. php?codArquivo=3564>. Acesso em: 12 de maio de 2012.

MARQUES, Tiago Miranda. Abordagens de recomendação para a recuperação de perfis: uma proposta de modelo. $197 \mathrm{f}$. Dissertação (Mestrado) - Faculdade de Ciência da Informação, Universidade de Brasília, 2007. Disponível em: <http://bdtd.bce.unb.br/tedesimplificado/tde busca/arquivo.php?codArquivo=2284>. Acesso em: 12 de maio de 2012.

MATTA, Rodrigo Octávio Beton. Oferta e demanda de informação financeira pessoal: o Programa de Educação Financeira do Banco Central do Brasil e os universitários do Distrito Federal. 201 f. Dissertação (Mestrado) - Faculdade de Ciência da Informação, Universidade de Brasília, 2007. Disponível em:

<http://bdtd.bce.unb.br/tedesimplificado/tde busca/arquivo. php?codArquivo=1196>. Acesso em: 12 de maio de 2012.

MIRANDA, Silvânia Vieira de. Identificação de necessidades de informação e sua relação com competências informacionais: o caso da supervisão indireta de instituições financeiras no Brasil. 293 f. Tese (Doutorado) - Faculdade de Ciência da Informação, Universidade de Brasília, 2007. Disponível em: <http://bdtd.bce.unb.br/tedesimplificado/tde busca/arquivo. php?codArquivo=1195>. Acesso em: 12 de maio de 2012.

NETO, Cleone Silvestre. Estudo de necessidades de informação dos produtores de hortaliças orgânicas não certificados do Distrito Federal. 151 f. Dissertação (Mestrado) - Faculdade de Ciência da Informação, Universidade de Brasília, 2010. Disponível

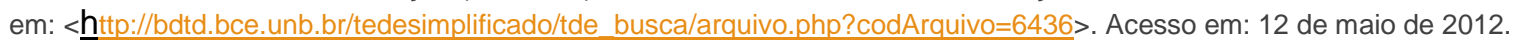

OLIVEIRA, Symball Rufino. Uma avaliação do raciocínio baseado em casos aplicado a recuperação de jurisprudência no Tribunal Regional Eleitoral do Distrito Federal. 141 f. Dissertação (Mestrado) - Faculdade de Ciência da Informação, Universidade de Brasília, 2008. Disponível em:

<http://bdtd.bce.unb.br/tedesimplificado/tde busca/arquivo.php?codArquivo=5534>. Acesso em: 12 de maio de 2012.

RODRIGUES, Carlos Zalberto. A necessidade de informação dos conselheiros de saúde. 192 f. Tese (Doutorado) - Faculdade de Ciência da Informação, Universidade de Brasília, 2009. Disponível em:

<http://www.cid.unb.br/m001/M0011000.asp?txtID PRINCIPAL=2>. Acesso em: 12 de maio de 2012.

SANTOS, Aleksandra Pereira. A memória na administração pública brasileira: diagnóstico da memória organizacional do Ministério do Planejamento, Orçamento e Gestão. 127 f. Dissertação (Mestrado) - Faculdade de Ciência da Informação, Universidade de Brasília, 2007. Disponível em:

$<$ http://bdtd.bce.unb.br/tedesimplificado/tde busca/arquivo. php?codArquivo=2307>. Acesso em: 12 de maio de 2012.

SANTOS, Eliane Pereira dos. Estudo sobre demanda e oferta de informação em saúde. 207 f.Dissertação (Mestrado) Faculdade de Ciência da Informação, Universidade de Brasília, 2009. Disponível em:

$<$ http://bdtd.bce.unb.br/tedesimplificado/tde busca/arquivo.php?codArquivo=5309>. Acesso em: 12 de maio de 2012.

SIMÃO, João Batista. A concepção de um modelo de cidade digital baseado nas necessidades informacionais do cidadão: 0 caso dos municípios brasileiros de pequeno porte. $132 \mathrm{f}$. Tese (Doutorado) - Faculdade de Ciência da Informação, Universidade de Brasília, 2010. Disponível em:

<http://bdtd.bce.unb.br/tedesimplificado/tde busca/arquivo.php?codArquivo=6796>. Acesso em: 12 de maio de 2012. 
TEIXEIRA, Fábio Augusto Guimarães. A recuperação da informação e a colaboração de usuário na Web. 159 f. Dissertação (Mestrado) - Faculdade de Ciência da Informação, Universidade de Brasília, 2010. Disponível em:

<http://bdtd.bce.unb.br/tedesimplificado/tde busca/arquivo. php?codArquivo=670 $\mathbf{8}$ >. Acesso em: 12 de maio de 2012.

\section{UNIVERSIDADE ESTADUAL PULISTA - UNESP - Marília}

BANHOS, Vangela Tatiana. Usabilidade na Recuperação de Informação: um enfoque no Catálogo Athena . 2008. $120 f$. Dissertação (Mestrado) - Faculdade de Filosofia e Ciências, Universidade Estadual Paulista, Marília, 2008. Disponível em: <http://www.marilia.unesp.br/Home/Pos-Graduacao/Cienciadalnformacao/Dissertacoes/banhos vt me mar.pdf>. Acesso em: 14 maio 2012.

BOCCATO, Vera Regina Casari. Avaliação do uso de linguagem documentária em catálogos coletivos de bibliotecas universitárias: um estudo sociocognitivo com protocolo verbal. 303f. Tese (Doutorado) - Faculdade de Filosofia e Ciências, Universidade Estadual Paulista, Marília, 2009. Disponível em: <http://www. marilia.unesp.br/Home/PosGraduacao/Cienciadalnformacao/Dissertacoes/boccato vrc do mar.pdf>. Acesso em: 14 maio 2012.

CAVALCANTE, Luciane de Fátima Beckman. Gestão do comportamento informacional apoiada na cultura organizacional e em modelos mentais. 2010. 240f. Dissertação (Mestrado) - Faculdade de Filosofia e Ciências, Universidade Estadual Paulista, Marília, 2010. Disponível em: <http://www. marilia.unesp.br/Home/Pos-

Graduacao/Cienciadalnformacao/Dissertacoes/cavalcanti Ifb me mar.pdf>. Acesso em: 14 maio 2012.

CONEGLIAN, André Luís Onório. Análise do comportamento informacional de pósgraduandos surdos: subsídios teóricopráticos para a organização e representação do conhecimento. 2008. 165f. Dissertação (Mestrado) - Faculdade de Filosofia e Ciências, Universidade Estadual Paulista, Marília, 2008. Disponível em: < http://www.marilia.unesp.br/Home/PosGraduacao/Cienciadalnformacao/Dissertacoes/coneglian alo me mar.pdf>. Acesso em: 14 maio 2012.

EUCLIDES, Maria Luzinete. Representação das necessidades de Informação na organização da informação: uma análise dos modelos teóricos de busca. 2007. 112f. Dissertação (Mestrado) - Faculdade de Filosofia e Ciências, Universidade Estadual Paulista, Marília, 2007. Disponível em: <>. Acesso em: 14 maio 2012. Disponível em: <http://www.marilia.unesp.br/Home/PosGraduacao/Cienciadalnformacao/Dissertacoes/euclides ml me mar.pdf>. Acesso em: 14 maio 2012.

GAMA, Fernando Alves da. As Contribuições das Linguagens de Marcação para a Gestão da Informação Arquivística Digital. 2011. 165 f. Dissertação (Mestrado) - Faculdade de Filosofia e Ciências, Universidade Estadual Paulista, Marília, 2011. Disponível em: <http://www.marilia.unesp.br/Home/Pos-Graduacao/Cienciadalnformacao/Dissertacoes/gama fa me mar.pdf>. Acesso em: 14 maio 2012.

GARCIA, Rodrigo Moreira. Modelos de comportamento de busca de informação: contribuições para a Organização da Informação. 2007. 122f. Dissertação (Mestrado) - Faculdade de Filosofia e Ciências, Universidade Estadual Paulista, Marília, 2007. Disponível em: <http://www.marilia.unesp.br/Home/Pos-Graduacao/Cienciadalnformacao/Dissertacoes/garcia rm me mar.pdf>. Acesso em: 14 maio 2012.

GUERRERO, Janaína Celoto. Competência informacional e a busca de informações científicas: um estudo com pósgraduandos da Faculdade de Ciências Agronômicas da UNESP campus de Botucatu. 2009. 111f. Dissertação (Mestrado) Faculdade de Filosofia e Ciências, Universidade Estadual Paulista, Marília, 2009. Disponível em: <http://www.marilia.unesp.br/Home/Pos-Graduacao/Cienciadalnformacao/Dissertacoes/querrero jc me mar.pdf >. Acesso em: 14 maio 2012.

LOUSADA, Mariana. Informação Orgânica como Insumo Estratégico para a Tomada de Decisão em Ambientes Competitivos. 2011. 250 f. Dissertação (Mestrado) - Faculdade de Filosofia e Ciências, Universidade Estadual Paulista, Marília, 2011. Disponível em: <http://www. marilia.unesp.br/Home/Pos-

Graduacao/Cienciadalnformacao/Dissertacoes/lousada m me mar.pdf >. Acesso em: 14 maio 2012.

MATTA, Rodrigo Octávio Beton. Aplicação do Modelo Transteórico de Mudança de Comportamento para o estudo do Comportamento Informacional de Usuários de Informação Financeira Pessoal. 2012. 273 f. Tese (Doutorado) - Faculdade de Filosofia e Ciências, Universidade Estadual Paulista, Marília, 2012. Disponível em: <http://www. marilia.unesp.br/Home/PosGraduacao/Cienciadalnformacao/Dissertacoes/matta rob do mar.pdf >. Acesso em: 14 maio 2012.

SANTOS, Fernando Bittencourt dos. Comportamento de busca da informação ambiental por pesquisadores da área de meio ambiente. 2008. 99f. Dissertação (Mestrado) - Faculdade de Filosofia e Ciências, Universidade Estadual Paulista, Marília, 2008. Disponível em: <http://www. marilia.unesp.br/Home/Pos-Graduacao/Cienciadalnformacao/Dissertacoes/santos fb me mar.pdf>. Acesso em: 14 maio 2012.

SILVA, Marli Vítor da. O comportamento informacional de advogados: um estudo com profissionais que atuam na cidade de Marília e região. 2010. 114f. Dissertação (Mestrado) - Faculdade de Filosofia e Ciências, Universidade Estadual Paulista, Marília, 2010. Disponível em: <http://www. marilia.unesp.br/Home/Pos-

Graduacao/Cienciadalnformacao/Dissertacoes/silva mv me mar.pdf>. Acesso em: 14 maio 2012. 
XAVIER, Raphael Figueiredo. Análise de Métodos de Produção de Interfaces Visuais para Recuperação da Informação. 2009. 78 f. Dissertação (Mestrado) - Faculdade de Filosofia e Ciências, Universidade Estadual Paulista, Marília, 2009. Disponível em: <http://www.marilia.unesp.br/Home/Pos-Graduacao/Cienciadalnformacao/Dissertacoes/xavier if me mar.pdf>. Acesso em: 14 maio 2012.

\section{UNIVERSIDADE DE SÃO PAULO - USP - São Paulo}

GONÇALVES, Aline Lima. Serviço de informação sobre deficiência: desafios para organização da informação. 232 f. Dissertação (Mestrado) - Escola de Comunicações e Artes, Universidade de São Paulo, 2010. Disponível em: < http://www.teses.usp.br/teses/disponiveis/27/27151/tde-05112010-104413/pt-br.php>. Acesso em: 12 de maio de 2012.

MATOS, Alexandra Linda Herbst. Documentação Musical: discussão sobre a representação temática de partituras a partir de um enfoque interdisciplinar. 104f. Dissertação (Mestrado) - Escola de Comunicações e Artes, Universidade de São Paulo, 2007. Disponível em: < http://www.pos.eca.usp.br/sites/default/files/File/dissertacoes/2007/2007-me-matos alexandra.pdf>. Acesso em: 22 de maio 2012.

REIS, Guilhermo Almeida dos. Centrando a Arquitetura de Informação no usuário. 250 f. Dissertação (Mestrado) - Escolha de Comunicações e Artes, Universidade de São Paulo, 2007. Disponível em: <

http://www.pos.eca.usp.br/sites/default/files/File/dissertacoes/2007/2007-me-reis guilhermo.pdf>. Acesso em: 22 de maio de 2012.

SILVA, Fábio Mascarenhas e. Organização da Informação em sistemas eletrônicos de Informação Científica e Tecnológica. Análise da Platarforma Lattes. 149 f. Tese (Doutorado) - Escola de Comunicações e Artes, Universidade de São Paulo, 2007. Disponível em: < http://www.pos.eca.usp.br/sites/default/files/File/dissertacoes/2008/2008-do-silva fabio.pdf >. Acesso em: 12 de maio de 2012.

SOUSA, Margarida Maria de. A biblioteca universitária como ambiente de aprendizagem no ensino superior. $90 \mathrm{f}$. Dissertação (Mestrado) - Escola de Comunicações e Artes, Universidade de São Paulo, 2009. Disponível em: < http://www.pos.eca.usp.br/sites/default/files/File/dissertacoes/2009/2009-me-sousa margarida.pdf>. Acesso em: 12 de maio de 2012.

\section{UNIVERSIDADE FEDERAL FLUMINENSE - UFF - Rio de Janeiro}

BARÇANTE, Eduardo. Proposta e metodologias de processamento automático de documentos textuais digitais: uma análise da literatura. 100 f. Dissertação (Mestrado) - Departamento de Ciência da Informação, Universidade Federal Fluminense, 2011. Disponível em: <http://www.ci.uff.br/ppgci/arquivos/Dissert/Diss EduardoBarcante.pdf>. Acesso em: 12 de maio de 2012.

DELAIA, Cláudia Regina. Subsídios para uma política de gestão da informação da Embrapa solos - à luz do regime de informação. 137 f. Dissertação (Mestrado) - Departamento de Ciência da Informação, Universidade Federal Fluminense, 2008. Disponível em: <http://ibict.phlnet.com.br/anexos/DelaiaClaudia2008.pdf>. Acesso em: 12 de maio de 2012.

RIBEIRO, Cláudio José Silva. Diretrizes para o projeto de portais de informação: uma proposta interdisciplinar baseada na Análise de Domínio e Arquitetura da Informação. 285 f. Tese (Doutorado) - Departamento de Ciência da Informação, Universidade Federal Fluminense, 2008. Disponível em: <http://ibict.phlnet.com.br/anexos/claudioribeiro2008.pdf>. Acesso em: 12 de maio de 2012.

VELHO, Ana Cristina Meirelles. A tomada de decisão na previdência social: uma reflexão sobre as ações do produtor de informações da dataprev. 136 f. Dissertação (Mestrado) - Departamento de Ciência da Informação, Universidade Federal Fluminense, 2007. Disponível em: <http://www.bdtd.ndc. uff.br/tde busca/arquivo. php?codArquivo=2354>. Acesso em: 12 de maio de 2012.

\section{UNIVERSIDADE FEDERAL DO RIO DE JANEIRO - UFRJ - Rio de Janeiro}

ALMEIDA, Tatiana de. O vocabulário controlado como instrumento de organização e representação da informação na UNESP. 149 f. Dissertação (Mestrado) - Universidade Federal do Rio de Janeiro, Instituto Brasileiro de Informação em Ciência e Tecnologia, 2011. Disponível em: <http://tede-dep.ibict.br/tde busca/arquivo.php?codArquivo=82>. Acesso em: 12 de maio de 2012.

BARROS, Léa Maria de Souza. A folksonomia como prática de classificação colaborativa para recuperação da informação. 90 f. Dissertação (Mestrado) - Universidade Federal do Rio de Janeiro, Instituto Brasileiro de Informação em Ciência e Tecnologia, 2011. Disponível em: <http://tede-dep.ibict.br/tde busca/arquivo.php?codArquivo=76>. Acesso em: 12 de maio de 2012. 
BOTÃO, Antônio Victor Rodrigues. Recuperação da informação digital: a Norma Brasileira de Descrição Arquivística (NOBRADE) na descrição de material imagético. 91 f. Dissertação (Mestrado) - Universidade Federal do Rio de Janeiro, Instituto Brasileiro de Informação em Ciência e Tecnologia, 2011. Disponível em: <http://tede-

dep.ibict.br/tde busca/arquivo.php?codArquivo=99>. Acesso em: 12 de maio de 2012.

FIGUEIREDO, Márcia Feijão de. Busca e validação da informação imagética na web. 108 f. Dissertação (Mestrado) Universidade Federal do Rio de Janeiro, Instituto Brasileiro de Informação em Ciência e Tecnologia, 2011. Disponível em: < http://tede-dep.ibict.br/tde busca/arquivo.php?codArquivo=87>. Acesso em: 12 de maio de 2012.

GIORDANO, Rafaela Boeira. Da necessidade ao conhecimento: recuperação da informação na web em Ciência da Infomação. 145 f. Dissertação (Mestrado) - Universidade Federal do Rio de Janeiro, Instituto Brasileiro de Informação em Ciência e Tecnologia, 2011. Disponível em: <http://tede-dep.ibict.br/tde busca/arquivo.php?codArquivo=88>. Acesso em: 12 de maio de 2012.

\section{UNIVERSIDADE FEDERAL DA BAHIA - UFBA - Salvador}

AMARAL, Clarissa de Azevedo. Controle e uso da informação: estratégia de poder e dominação do grupo liderado por Antônio Carlos Magalhães (1985-2006). 265 f. Dissertação (Mestrado) - Instituto de Ciência da Informação, Universidade Federal da Bahia, 2007. Disponível em:<http://www. bibliotecadigital.ufba.br/tde arquivos/16/TDE-2009-03-19T123258Z-

1024/Publico/Dissertaca0\%20Clarissa\%20Maria\%20de\%20Azevedo\%20Amaralseg.pdf >. Acesso em: 12 de maio de 2012.

MARQUES, Kátia Cunha. O currículo lattes e a política científica no Brasil: objetividade e subjetividade. 158 f. Dissertação (Mestrado) - Instituto de Ciência da Informação, Universidade Federal da Bahia, 2009. Disponível em: < http://www.bibliotecadigital.ufba.br/tde busca/arquivo.php?codArquivo=3376 >. Acesso em: 12 de maio de 2012.

OLIVEIRA, Maria Dulce Paradella Matos de. Acesso e uso da informação em telecentros: um estudo em comunidades de baixa renda de Salvador. 156 f. Dissertação (Mestrado) - Instituto de Ciência da Informação, Universidade Federal da Bahia, 2008. Disponível em:<http://www.bibliotecadigital.ufba.br/tde arquivos/16/TDE-2009-08-28T143500Z1338/Publico/Dissertaca0\%20de\%20Maria\%20Dulce\%20Paradella\%20Matos\%20de\%20Oliveiraseg.pdf>. Acesso em: 12 de maio de 2012.

OLIVEIRA, Raimundo Muniz de. Biblioteca digital de teses e dissertações: grau de utilização pelos mestrandos do curso de ciência da informação das universidades públicas brasileiras. 114 f. Dissertação (Mestrado) - Instituto de Ciência da Informação, Universidade Federal da Bahia, 2009. Disponível em:

<http://www. bibliotecadigital.ufba.br/tde busca/arquivo. php?codArquivo=3927>. Acesso em: 12 de maio de 2012.

PERES, Ricardo Luís Rodrigues. O estudante universitário e a recuperação da informação na Internet. 126 f. Dissertação (Mestrado) - Instituto de Ciência da Informação, Universidade Federal da Bahia, 2008. Disponível em: <http://www. bibliotecadigital.ufba.br/tde busca/arquivo. php?codArquivo=2394>. Acesso em: 12 de maio de 2012.

SANTANA, Fausta Joaquina Clarinda de. Descontinuidades e sombras: acessos, usos e fontes de informação numa comunidade rural e remota na sociedade da informação. 214 f. Dissertação (Mestrado) - Instituto de Ciência da Informação, Universidade Federal da Bahia, 2009. Disponível em: <http://www. bibliotecadigital.ufba.br/tde busca/arquivo.php?codArquivo=3409>. Acesso em: 12 de maio de 2012.

VELASCO, Juliana Oliveira. O uso do livro eletrônico na prática científica. 188 f. Dissertação (Mestrado) - Instituto de Ciência da Informação, Universidade Federal da Bahia, 2008. Disponível em:< http://www.bibliotecadigital.ufba.br/tde arquivos/16/TDE2010-10-29T135349Z-1966/Publico/Dissertacao\%20Juliana\%20Oliveira\%20Velascoseg.pdf>. Acesso em: 12 de maio de 2012.

ZAIDAN, Rosana Lima. Competências para acesso e uso da informação em sistemas de EAD: análise do curso interagindo e construindo na rede. 167 f. Dissertação (Mestrado) - Instituto de Ciência da Informação, Universidade Federal da Bahia, 2010. Disponível em: <http://www.bibliotecadigital.ufba.br/tde busca/arquivo.php?codArquivo=3949>. Acesso em: 12 de maio de 2012.

\section{UNIVERSIDADE FEDERAL DE SANTA CATARINA - UFSC - Florianópolis}

ABE, Veridiana. A busca de informação na internet: bibliotecários e estudantes de Ensino Médio de escolas particulares de Itajaí e Florianópolis. 144 f. Dissertação (Mestrado) - Centro de Ciências da Educação, Universidade Federal de Santa Catarina, 2009. Disponível em: <http://pgcin.paginas.ufsc.br/files/2010/10/ABE-Veridiana.pdf>. Acesso em: 12 de maio de 2012.

ALVORCEM, Rochelle Martins. O sistema eletrônico de editoração de revistas e sua navegabilidade: um estudo no fluxo do processo editorial no Portal de Periódicos da UFSC. 194 f. Dissertação (Mestrado) - Centro de Ciências da Educação, Universidade Federal de Santa Catarina, 2010. Disponível em: < http://pgcin.paginas. ufsc.br/files/2010/10/ALVORCEM-RochelleMartins.pdf>. Acesso em: 12 de maio de 2012. 
BARROS, Camila Monteiro. Representação da informação musical: subsídios para recuperação da informação em registros sonoros e partituras no contexto educacional e de pesquisa. 150 f. Dissertação (Mestrado) - Centro de Ciências da Educação, Universidade Federal de Santa Catarina, 2012. Disponível em: <http://pgcin.paginas.ufsc.br/files/2010/10/BARROS-CamilaMonteiro-de.pdf>. Acesso em: 12 de maio de 2012.

BEDIN, Sonali Paula Molin. Metodologia para validação de ontologias: o caso ORBIS_MC. 108 f. Dissertação (Mestrado) Centro de Ciências da Educação, Universidade Federal de Santa Catarina, 2007. Disponível em: <http://pgcin.paginas.ufsc.br/files/2010/10/BEDIN-Sonali.pdf>. Acesso em: 12 de maio de 2012.

DÁVILLA CALLE, Guillermo Antônio. Fluxos de informação como suporte à tomada de decisões: um modelo de análise. $130 \mathrm{f}$. Dissertação (Mestrado) - Centro de Ciências da Educação, Universidade Federal de Santa Catarina, 2008. Disponível em: $<$ http://pgcin.paginas.ufsc.br/files/2010/10/CALLE-Guillermo.pdf>. Acesso em: 12 de maio de 2012.

FAZZIONI, Dilva Páscoa De Marco. A competência informacional em pacientes hipertensos. 177 p. Dissertação (Mestrado) Centro de Ciências da Educação, Universidade Federal de Santa Catarina, 2011. Disponível em: < http://pgcin.paginas.ufsc.br/files/2010/10/FAZZIONI-Dilva.pdf>. Acesso em: 12 de maio de 2012.

FLORIANI, Vivian Mengarda. Análise do fluxo informacional como subsídio ao processo de tomada de decisões em um órgão municipal de turismo. 199 f. Dissertação (Mestrado) - Centro de Ciências da Educação, Universidade Federal de Santa Catarina, 2007. Disponível em: <http://pgcin.paginas.ufsc.br/files/2010/10/FLORIANI-Vivian1.pdf>. Acesso em: 12 de maio de 2012.

MOLOSSI, Sinara. Inserção da Biblioteca Digital de Teses e Dissertações no contexto da Web Semântica: construção e uso da ontologia. 214 f. Dissertação (Mestrado) - Centro de Ciências da Educação, Universidade Federal de Santa Catarina, 2008. Disponível em: <http://pgcin.paginas.ufsc.br/files/2010/10/MOLOSSI-Sinara.pdf>. Acesso em: 12 de maio 2012.

WENSIG, Jairo. Preservação e recuperação de informação em fontes de informação digitais: estudo de caso do Greenstone. 219 f. Dissertação (Mestrado) - Centro de Ciências da Educação, Universidade Federal de Santa Catarina, 2010. Disponível em: < http://pgcin.paginas.ufsc.br/files/2010/10/WENSING-Jairo.pdf> Acesso em: 12 de maio de 2012.

\section{UNIVERSIDADE FEDERAL DA PARAÍBA - UFPB - João Pessoa}

BARROS, Dirlene Santos. Dimensões Metacognitivas no Comportamento de Busca de Informação: Estudo de usuário no Arquivo Público do Estado do Maranhão (APEM). 156 f. Dissertação (Mestrado) - Departamento de Ciência da Informação, Universidade Federal da Paraíba, 2009. Disponível em:< http://dci2.ccsa.ufpb.br:8080/ispui/bitstream/123456789/100/1/disserta\%C3\%A7\%C3\%A3odefinitiva.pdf>. Acesso em: 12 de maio de 2012.

COSTA, Luciana Ferreira da. Usabilidade do Portal de Periódicos da CAPES. 236 f. Dissertação (Mestrado) - Departamento de Ciência da Informação, Universidade Federal da Paraíba, 2008. Disponível em: <

http://dci2.ccsa.ufpb.br:8080/ispui/bitstream/123456789/99/3/Disserta\%C3\%A7\%C3\%A30\%20Luciana\%20Costa.pdf >. Acesso em: 12 de maio de 2012

DUARTE, Janete Silva. Uso do Portal de Periódicos da CAPES pelos alunos do Programa de Pós-Graduação em produtos naturais e sintéticos bioativos. 122 f. Dissertação (Mestrado) - Departamento de Ciência da Informação, Universidade Federal da Paraíba, 2010. Disponível em: <

http://dci2.ccsa.ufpb.br:8080/ispui/bitstream/123456789/648/1/disserta\%C3\%A7\%C3\%A30\%20\%20USO\%20DO\%20PORTAL\%20 DA\%20CAPES.pdf>. Acesso em: 12 de maio de 2012.

LIMA, Celly de Brito. Identidades afrodescendentes acesso e democratização da informação na cibercultura. $115 \mathrm{f}$. Dissertação (Mestrado) - Departamento de Ciência da Informação, Universidade Federal da Paraíba, 2009. Disponível em: < http://dci2.ccsa.ufpb.br:8080/ispui/bitstream/123456789/166/1/Disserta\%C3\%A7\%C3\%A3o Celly Lima PPGCl UFPB.pdf>. Acesso em: 12 de maio de 2012.

MACIEL ALBUQUERQUE, Ednaldo. Necessidades e uso de informação: um estudo com médicos de Unidades de Saúde da Família. 160 f. Dissertação (Mestrado) - Departamento de Ciência da Informação, Universidade Federal da Paraíba, 2010. Disponível em: <

http://dci2.ccsa.ufpb.br:8080/ispui/bitstream/123456789/630/1/NECESSIDADES\%20E\%20USO\%20DE\%20INFORMA\%C3\%87\%C $3 \% 830 \% 20-$

\%20um\%20estudo\%20com\%20m\%C3\%A9dicos\%20de\%20Unidades\%20de\%20Sa\%C3\%BAde\%20da\%20Fam\%C3\%ADlia.pdf>. Acesso em: 12 de maio de 2012.

SALES, Esmeralda Porfírio de. Análise das barreiras na comunicação da informação para tomada de decisão: o caso do Instituto de Metrologia e Qualidade Industrial da Paraíba. 96 f. Dissertação (Mestrado) - Departamento de Ciência da Informação, Universidade Federal da Paraíba, 2010. Disponível em: <

http://dci2.ccsa.ufpb.br:8080/jspui/bitstream/123456789/654/1/Disserta\%C3\%A7\%C3\%A30\%20Esmeralda\%20Porfirio\%20de\%20S ales.pdf >. Acesso em: 12 de maio de 2012. 
SANTIAGO, Sandra Maria Neri. Um olhar para a educação de usuários do sistema integrado de bibliotecas da Universidade Federal de Pernambuco. 167 f. Dissertação (Mestrado) - Departamento de Ciência da Informação, Universidade Federal da Paraíba, 2011. Disponível em: <http://dci2.ccsa.ufpb.br:8080/jspui/bitstream/123456789/673/1/DissertSandraNeri.pdf>. Acesso em: 12 de maio de 2012.

SILVA, Patrícia Maria. Modelo de aceitação de tecnologia (TAM) aplicado ao sistema de informação da biblioteca virtual em saúde (BVS) nas escolas de medicina da região metropolitana do Recife. 154 f. Dissertação (Mestrado) - Departamento de Ciência da Informação, Universidade Federal da Paraíba, 2008. Disponível em: < http://dci2.ccsa.ufpb.br:8080/ispui/bitstream/123456789/40/1/Disserta\%C3\%A7\%C3\%A30\%20Patr\%C3\%ADcia\%20Silva.pdf>. Acesso em: 12 de maio de 2012.

\section{UNIVERSIDADE ESTADUAL DE LONDRINA - UEL - Londrina}

AMORIM, Fabiana Regina Borelli. O compartilhamento de informações por sistema baseado em computador: estudo na prefeitura do município de Londrina. 150 f. Dissertação (Mestrado) - Departamento de Ciência da Informação, Universidade Estadual de Londrina, 2010. Disponível em: < http://www.bibliotecadigital.uel.br/document/?view=vtls000156635>. Acesso em: 12 de maio de 2012.

CSISZER, Cassiano Ricardo. Comportamento informacional de gestores de uma agência de propaganda. 102 f. Dissertação (Mestrado) - Departamento de Ciência da Informação, Universidade Estadual de Londrina, 2010. Disponível em:

$<$ http://www.bibliotecadigital.uel.br/document/?view=vtls000161240>. Acesso em: 12 de maio de 2012.

GOMES, Silvio Rogério Felipe. Compartilhamento da informação como subsídio para o processo decisório: estudo de caso da cadeia produtiva avícola o significado para o usuário. 191 f. Dissertação (Mestrado) - Departamento de Ciência da Informação, Universidade Estadual de Londrina, 2010. Disponível em: <http://www.bibliotecadigital.uel.br/document/?view=vtls000161118>.

Acesso em: 12 de maio de 2012

NISHITANI, Paulo Kiyoshi. Gestão documental em agências bancárias: estudo de caso em um banco da cidade de Londrina. 146 f. Dissertação (Mestrado) - Departamento de Ciência da Informação, Universidade Estadual de Londrina, 2010. Disponível em: $<$ http://www.bibliotecadigital.uel.br/document/?view=vtls000157271>. Acesso em: 12 de maio de 2012.

\section{Dados dos autores}

\section{Vitor Taga}

Mestrado em andamento (início 2010) em Ciência da Informação pela Universidade Federal de Santa Catarina. Possui graduação em Biblioteconomia pela Universidade Federal de Goiás (2008).

vitor.taga@gmail.com

\section{Ursula Blattmann}

Professora na Universidade Federal de Santa Catarina. Atua no Departamento de Ciência da Informação. Subcoordenadora do Curso de Graduação em Arquivologia e do Curso de Graduação em Biblioteconomia. ursula@ced.ufsc.br

Recebido - Received : 2012-06-13

Aprovado - Accepted: 2012-09-29

\section{(cc) EY-NC-ND}

This work is licensed under a Creative Commons

Attribution-Noncommercial-No Derivative Works 3.0 United States License.

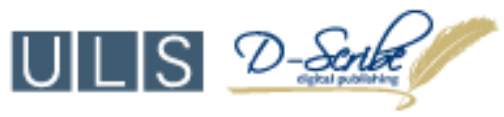

This journal is published by the University Library System of the University of Pittsburgh as part of its D-Scribe Digital Publishing Program and is cosponsored by the University of Pittsburgh Press. 